\title{
HUISGEN AND HIS ADVENTURES IN A PLAYGROUND OF MECHANISMS AND NOVEL REACTIONS
}

\author{
Daniel T. G. Gonzaga, ${ }^{a}$ Luana da S. M. Forezi, ${ }^{b}$ Carolina G. de S. Lima, ${ }^{b}$ Patricia G. Ferreira, ${ }^{c}$ Fernando de C. da Silva ${ }^{(b}$ \\ and Vitor F. Ferreira ${ }^{\mathrm{c}, *,(1)}$ \\ anidade de Farmácia, Fundação Centro Universitário Estadual da Zona Oeste, 23070-200 Rio de Janeiro - RJ, Brasil \\ bDepartamento de Química Orgânica, Instituto de Química, Universidade Federal Fluminense, 24020-150 Niterói - RJ, Brasil \\ 'Departamento de Tecnologia Farmacêutica, Faculdade de Farmácia, Universidade Federal Fluminense, 24241-000 Niterói - RJ, \\ Brasil
}

Recebido em 09/06/2020; aceito em 09/09/2020; publicado na web em 15/10/2020

\begin{abstract}
The death of professor Rolf Huisgen (1920-2020) was announced on March 26 ${ }^{\text {th }}$ 2020, in the midst of the COVID-19 pandemic. Professor Huisgen was professor emeritus at the University of Munich in Germany, and studied in detail the mechanism of the 1,3-dipolar cycloaddition reaction, significantly expanding its scope. Even though he did not discover this reaction, it was through his studies that it became important in organic synthesis. Indeed, in honor of his work, the reaction became known as Huisgen's cycloaddition and it has been consolidated as a useful method for the preparation of five-membered heterocyclic compounds. Considering these facts, in this review we provide an overview on the applications of 1,3-dipolar cycloaddition reactions, starting with the seminal examples in the field and further discussing the most recent applications.
\end{abstract}

Keywords: 1,3-dipolar cycloaddition; azide; alkyne; 1,2,3-triazole; click chemistry.

\section{INTRODUCTION}

Rolf Huisgen (Figure 1) was a German scientist whose research, focused on the study of organic reaction mechanisms and how orbital control influences reactivity, revolutionized the chemistry scene. This article is a tribute to the life of a great chemist who contributed plentifully to the development of organic chemistry, and its title is an adaptation of his autobiographical book. ${ }^{1}$ During the writing of this article, a mini-review was published in memory of professor Rolf Huisgen dealing with various aspects of his personal life, development of the university where he worked and important details on his 1,3-dipolar cycloaddition chemistry. ${ }^{2}$

Professor Huisgen was born in Gerolstein, Germany, on June $13^{\text {th }}$ 1920. He studied chemistry at the universities of Bonn and Munich, both in Germany, and received his Ph.D. in organic chemistry from the University of Munich in 1943 under the supervision of Heinrich Otto Wieland. After completing his Ph.D. and his habilitation in 1947, he became a professor at the University of Tübingen in 1949, where he stayed from 1949 to 1952 . He returned to the University of Munich in 1952 as full professor of organic chemistry, and remained there until his retirement in 1988, from where he continued his research as Emeritus Professor.

During his career, Huisgen supervised several doctoral theses, and many of his students became renowned professors. The chemist Ivar Karl Ugi (1930-2005), for instance, obtained his doctorate under Huisgen guidance in 1954, and became a professor at the Technical University of Munich, having developed the reaction that turned out to be known as the multicomponent Ugi reaction. Bernd Giese received his doctorate in 1969 and became a full professor at the University of Basel, while Johann Gasteiger got his Ph.D. in 1971 and became a full professor at the University of Erlangen - Nuremberg in the "Computer-Chemie-Centrum", which he co-founded. Another illustrious student was Herbert Mayr, who obtained his doctorate in 1974 and currently is a professor at the Ludwig-MaximiliansUniversität München, where he develops research on kinetics of

*e-mail: vitorferreira@id.uff.br polar organic and metal-organic reactions. Among many others, Hans-Ulrich Reissig is currently a professor of chemistry at Freie Universität Berlin, with diverse interests in the chemistry of donoracceptor cyclopropanes, and Reinhard Brückner, who obtained his doctorate in 1984 and is currently a professor at the University of Freiburg.

It is noteworthy that professor Huisgen was a member of the German National Academy of Sciences Leopoldina, the American Academy of Arts and Sciences, and the U.S. National Academy of Sciences. He was also an Honorary Fellow of the Royal Society of Chemistry (RSC) and an Honorary Member of the Gesellschaft Deutscher Chemiker (GDCh, German Chemical Society) and the Chemical Society of Japan (CSJ). Among many other honors, he received the Liebig Medal from the GDCh in 1961, the Lavoisier Medal from the Société Chimique de France (SCF, French Chemical Society) in 1965, and the Adolfo Quilico Medal from the Società Chimica Italiana (SCI, Italian Chemical Society) in 1987, as well as multiple honorary doctorates.

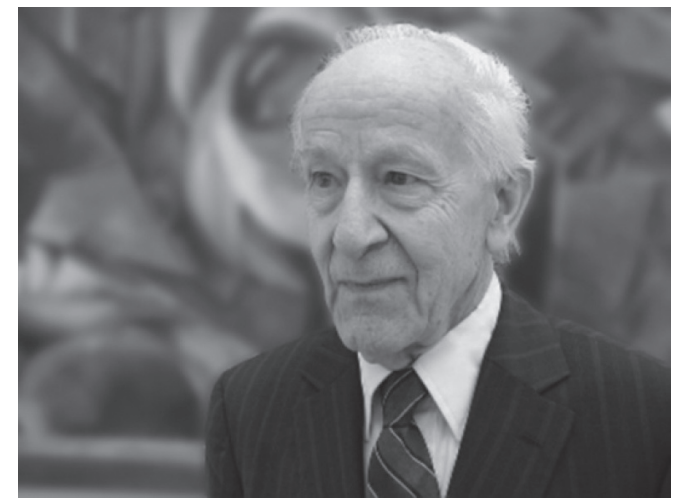

Figure 1. Picture of professor Rolf Huisgen ${ }^{3}$

Although Huisgen studied several reactions, he became particularly famous in academia for his work on 1,3-dipolar cycloaddition (1,3-DC) reactions. This reaction was already known in the literature, but Huisgen 
studied it in detail and vastly expanded its applications. Indeed, such reaction is currently named "the Huisgen's cycloaddition reaction", or "Huisgen's reaction", and has been applied in the synthesis of many heterocyclic compounds to date. Several reviews have already been published on 1,3-dipolar cycloadditions, ${ }^{3-6}$ and therefore, this is a welldocumented reaction with solid theoretical and experimental basis that explain its generality, kinetics and mechanisms. ${ }^{7-10}$

From a historical point of view, the 1,3-DC reaction has been known since the $18^{\text {th }}$ century, and it is worth highlighting the work developed by E. Buchner (1907 Nobel laureate), which described the 1,3-DC of diazo acetic ester with $\alpha, \beta$-unsaturated esters. ${ }^{11}$ On the other hand, the 1,3-dipolar cycloaddition reaction only flourished as valuable tool for organic synthesis after the studies conducted by Huisgen. Smith's 1938 revision showed the state of the art of aliphatic diazo compounds, nitrones, azides and other structurally similar analogues that are capable of undergoing 1,3-DC and the exceptional possibilities that these reactions offered by then in the preparation of new heterocyclic compounds. ${ }^{12}$

The 1,3-cycloaddition reaction so brilliantly described by Huisgen paved the path for the development of synthetic methods toward several types of heterocyclic compounds. Considering all these facts, in this review we provide a brief discussion on the mechanism and overall features of this type of reaction, followed by an outline of the different compounds that can be obtained using such protocols. We start by discussing general aspects and the mechanism of this reaction, go through seminal examples and discuss the most recent promising applications.

\section{1,3-DIPOLAR CYCLOADDITION REACTIONS: GENERAL ASPECTS AND MECHANISMS}

The 1,3-dipolar cycloaddition is one of the most versatile methods in organic synthesis, since it enables the access to a large number of five-membered heterocycles. This reaction is a particular type of the general class of pericyclic reactions, which are concerted reactions that proceed via a transition state and do not involve the formation of intermediaries. Such reactions cannot be described in terms of nucleophile-electrophile interactions, and it is not possible to discern the type of transition state via radicals or ionic intermediates. Decades ago, Robert B. Woodward (1965 Nobel Prize) and Roald Hoffmann (1981 Nobel Prize) defined a pericyclic reaction as "a reaction in which all changes in chemical bonds in a cycle are first order and occur in concert". ${ }^{13}$ Pericyclic reactions can be divided into 4 classes: electrocyclic reactions, sigmatropic rearrangements, ene reactions and cycloaddition reactions (Figure 2). ${ }^{14}$

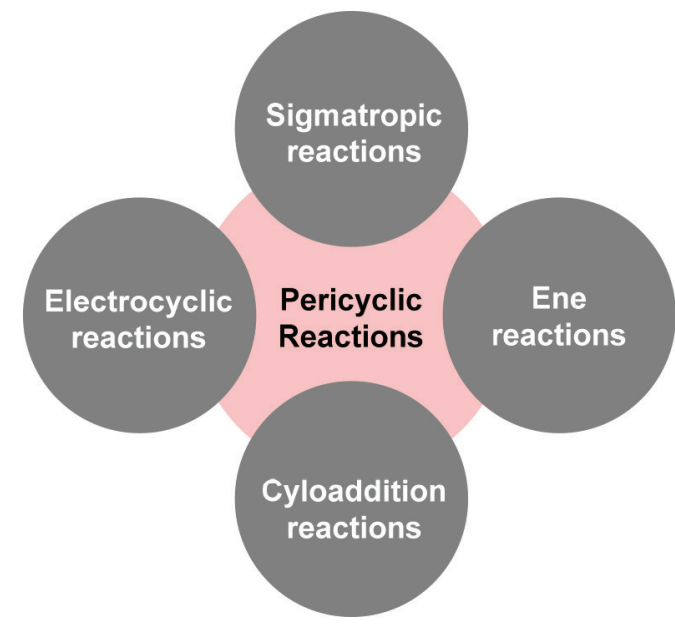

Figure 2. Types of pericyclic reactions
The cycloaddition reaction involves the concerted formation of two $\sigma$ bonds at the expense of one or two $\pi$ bonds, and it can occur either inter- or intramolecularly. They can be classified according to the number of bonds formed or the size of the ring in the product, and thermal/photochemical cycloaddition reactions can produce 4-, 5- and 6-membered rings.

The 1,3-dipolar cycloaddition occurs between $(3+2)$ atoms, and is a particular case of the cycloaddition reactions involving six electrons, the $[4+2]$ cycloadditions. In this type of reaction, a compound containing a 1,3-dipolar group (dipole) interacts with another one containing a $\pi$ system (dipolarophile). The most wellknown dipolar molecules contain the azide, nitro, nitrile oxide, nitric oxide, ozone, nitrone and the diazo groups. In the a 1,3-dipole represented as a-b-c, the atom "a" has a positive formal charge, while the "c" atom has an unshared electron pair and is negatively charged, these two poles being connected via a double or triple bond (Scheme 1). Similarly, to the dipoles, several substances that contain double and triple bonds can be used as dipolarophiles in 1,3-dipolar cycloaddition reactions. ${ }^{15}$

1,3-Dipoles are ambivalent species, but their nucleophilic or electrophilic character can predominate to variable degrees. Their 1,3 -DC are described by pairs of $\pi$-HOMO (Highest Occupied Molecular Orbital) - LUMO (Lowest Unoccupied Molecular Orbital) interactions, which are located on a continuum between HOMO (1,3-dipole)-LUMO (dipolarophile) control and LUMO (1,3-dipole)-HOMO (dipolarophile) control. At the two extremes of this scale, a mechanistic switch from a concerted to a twostep pathway via a zwitterionic intermediate is to be expected. The HOMO and LUMO energies of 1,3-dipoles are determined by the nature and number of heteroatoms, as well as by their substituents. ${ }^{16}$

In the last decades, experimental data have revealed details on the mechanism of the cycloaddition reactions: a) the addition is reversible; b) the rate of the reaction depends on both components; c) the reaction is second order with little influence from the solvent; d) additions to $Z$ or $E$ olefins are stereospecific, which suggests a concerted but not necessarily synchronized mechanism; e) the entropy of the process is strongly negative. These facts are better suited to a mechanism where the geometry of the transition state places the dipole's LUMO and the dipolarophile's HOMO in parallel planes, leaving the perpendicular orbitals in a favorable position for the formation of the $\sigma$ bonds (Scheme 2). The use of HOMO and LUMO Frontier Molecular Orbitals (FMO) to explain this type of reaction is relatively simple and reasonably accurate. ${ }^{17}$

Depending on the structures of the dipoles and dipolarophiles, 1,3-DC reactions can generate various isomers, e.g. regio-, diastereoand enantiomers. ${ }^{18-20}$ The formation of all possible isomers depends on the approach between the reagents, and the ratio of regioisomers is controlled by the lowest HOMO/LUMO energy gap. In this sense, three scenarios are possible (i) the dipole has a high-lying HOMO that interacts with the $\mathrm{LUMO}_{\text {dipolarophile }}$, being called HOMO-controlled; since this type of dipole is nucleophilic, it will promptly add to electrophilic alkenes, and thus, electron-withdrawing groups on the dipolarophile accelerate the reaction (ii) the dipole has a low-lying LUMO that interacts with the $\mathrm{HOMO}_{\text {dipolarophile }}$, being called LUMOcontrolled; the dipole in this case is electrophilic, and so, electrondonating groups in the dipolarophile will accelerate the reaction and (iii) the $\mathrm{HOMO}_{\text {dipole }}-\mathrm{LUMO}_{\text {dipolarophile }}$ and $\mathrm{HOMO}_{\text {dipolarophile }}-\mathrm{LUMO}_{\text {dipole }}$ energy gaps are similar, which cause both interactions to occur; the dipole is referred to as a HOMO-LUMO-controlled dipole and any groups that lower the energy gap between the two partners will accelerate the reaction.

In addition to the formation of the 1,4- and 1,5-regioisomers in 


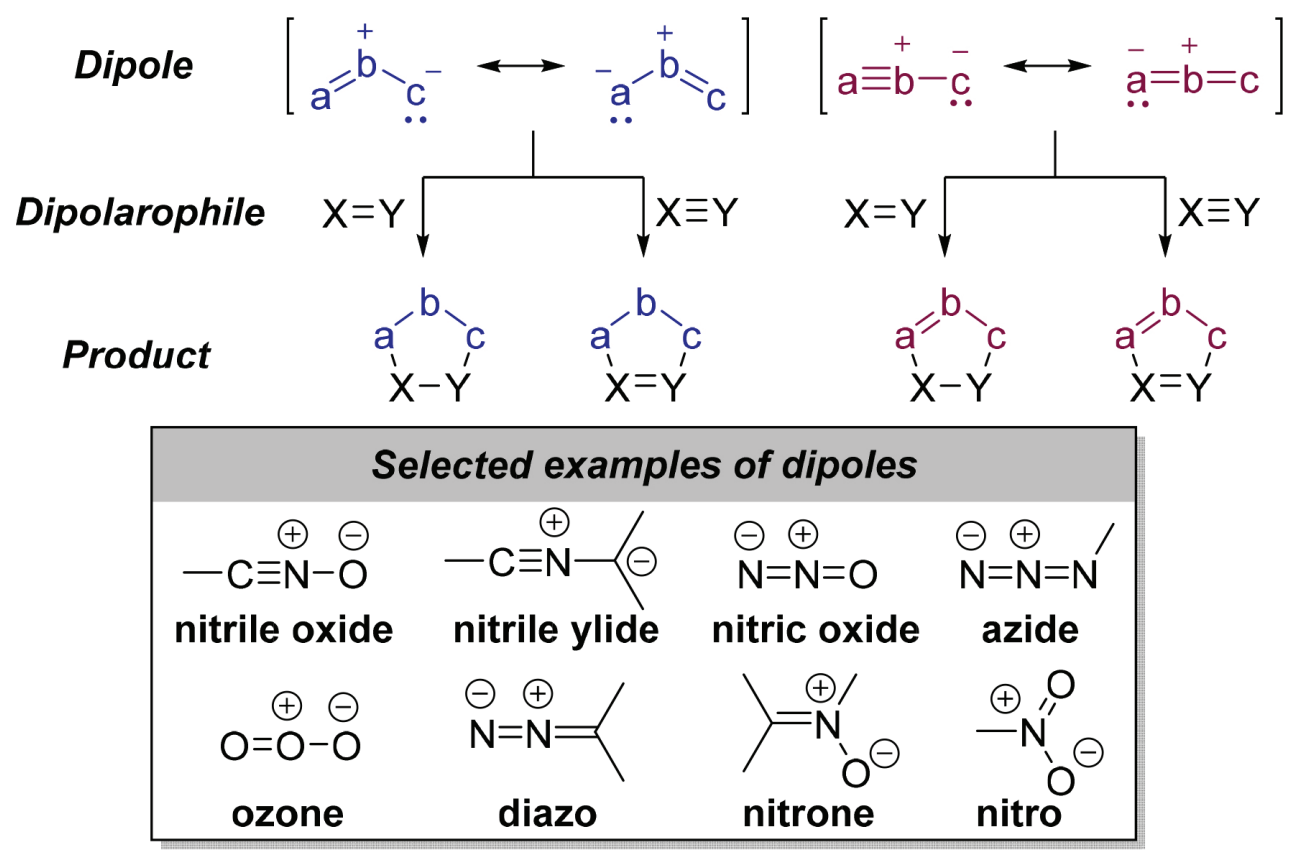

Scheme 1. General scheme of 1,3-dipolar reactions

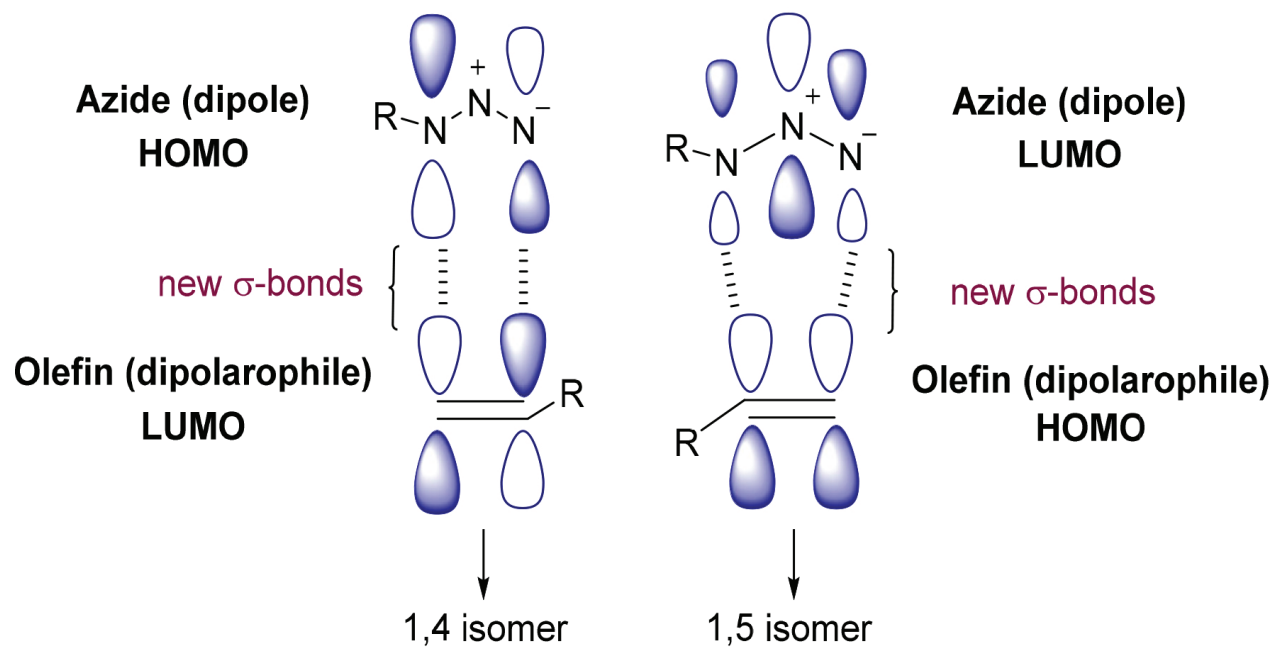

Scheme 2. Possible orbitals interaction in the transition state of an azide-alkene 1,3-dipolar cycloaddition

the cycloaddition between the 1,3-dipole and dipolarophile, there may be the formation of a pair of diastereoisomers resulting from the approach between the $4 \mathrm{e}^{-} \pi$ and $2 \mathrm{e}^{-} \pi$ systems known as endo or exo products. This cycloaddition follows the same principle as the Diels-Alder reaction, with the endo transient state displaying extra stabilization due to secondary orbital interactions. However, the endo/exo selectivity of the reaction can be altered by stereoelectronic factors, which decrease the influence of the stabilizing effect on the secondary interaction of orbitals. Scheme 3 shows an example of the reaction between a nitrone and an alkene, in which different regio- and diastereoisomeric products may be observed..$^{21,22}$

\section{1,3-DIPOLAR CYCLOADDITION REACTIONS : APPLICATIONS IN THE SYNTHESIS OF HETEROCYCLIC COMPOUNDS}

\section{Synthesis of 1,2,3- and 1,2,4-Triazoles}

Undoubtedly, in the last century the 1,3-DC reaction has become a powerful tool in the synthesis of important biologically active compounds. ${ }^{6,23}$ Indeed, the importance of this reaction is evidenced by the number of scientific publications on this subject: so far, there have been over 15,000 publications involving 1,3-DC.

Among the 1,3-DC reactions, the $(3+2)$-cycloaddition between organic azides and terminal alkynes for the synthesis of 1,2,3-triazoles has been one of the most explored, a consequence of the pronounced biological activity of such compounds. ${ }^{24}$ Back in 1893, Arthur Michael carried out the reaction between ethyl acetylene dicarboxylate $\mathbf{1}$ and aryl azides 2 to form 1,4,5-trisubstituted 1,2,3-triazoles $\mathbf{3}$ (Scheme 4a). ${ }^{25}$ In this case, since a symmetrical alkyne was employed, a single product is observed. However, when non-symmetrical alkynes are used, both the 1,4- and 1,5-disubstituted 1,2,3-triazole products can be formed, as showed in Scheme $4 \mathrm{~b}$.

Although the Huisgen 1,3-DC was a breakthrough that paved the path for the synthesis of several types of important compounds, its lack of regioselectivity was still regarded as a severe limiting issue. In order to overcome this problem, Tornøe and Sharpless independently reported in 2002 the development a variant of this process in which copper(I) is used as a catalyst to promote the reaction between terminal alkynes and organic azides. ${ }^{26,27}$ This copper-catalyzed 


\section{a) Nitrone-alkene 1,3-dipolar cycloaddition reaction}

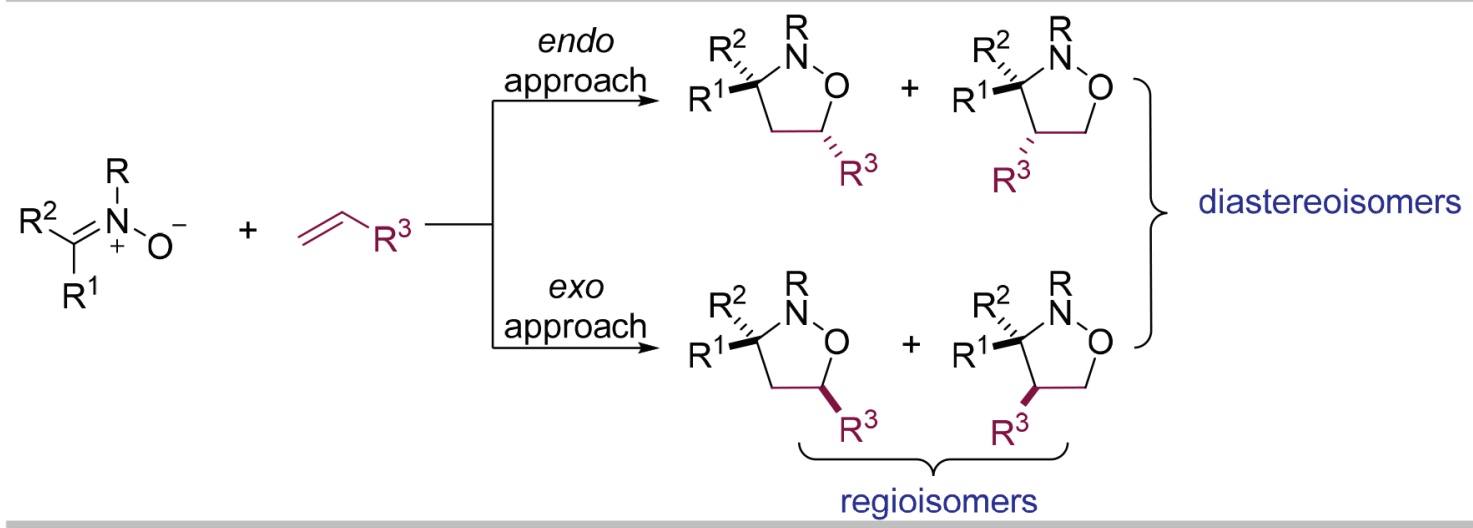

\section{b) HOMO-LUMO interactions}

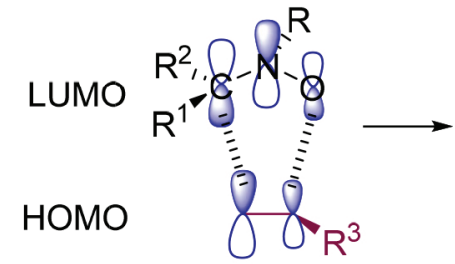<smiles>[R]C1CC([R])([R])N([R])O1</smiles>

1,5-product

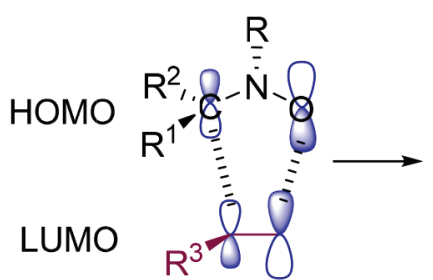<smiles>[R]C1CON([R])C1([R])[R]</smiles>

1,4-product

\section{c) The exolendo selectivity}

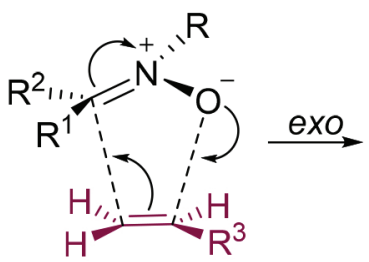<smiles>[R]C1CC([R])([R])N([R])O1</smiles>

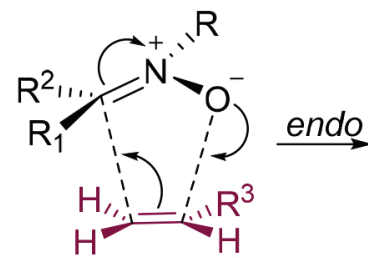<smiles>[R]C1CC([R])([R])N([R])O1</smiles>

Scheme 3. a) Example of a nitrone-alkene 1,3-dipolar cycloaddition reaction, b) representation of the frontier molecular orbitals involved in the reaction and c) exo and endo transient states involved in the process

\section{a) 1,3-dipolar cycloaddition between a symmetrical alkyne and an azide}

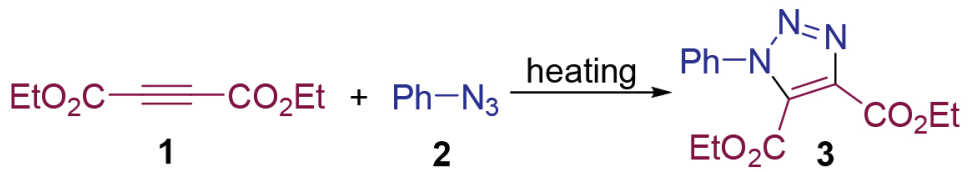

\section{b) 1,3-dipolar cycloaddition between a non-symmetrical alkyne and an azide}

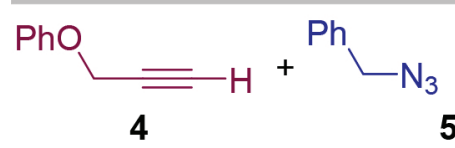

5<smiles>c1ccc(Cn2cc(COc3ccccc3)nn2)cc1</smiles>

6 1,4-disubstituted 1,2,3-triazole<smiles>c1ccc(Cn2nncc2COc2ccccc2)cc1</smiles>

7 1,5-disubstituted 1,2,3-triazole

Scheme 4. Preparation of 1,2,3-triazoles from azides and a) symmetrical and b) non-symmetrical alkynes

approach affords exclusively the 1,4-disubstituted-1,2,3-triazoles as products, and its mechanism can no longer be regarded as a true concerted cycloaddition reaction, since several intermediates are observed in the process. In this sense, the reaction is known as the copper(I)-catalyzed azide-alkyne cycloaddition (CuAAC). In this case, copper(II) sulfate pentahydrate was used to produce the catalytic copper(I) species in situ using sodium ascorbate as a reducing agent (Scheme $5 \mathrm{a}$ ). In the mechanism proposed by Fokin and Sharpless' group for the $\mathrm{CuAAC}$, the $\mathrm{Cu}(\mathrm{I})$ ion initially binds to the terminal alkyne $\mathbf{8}$ forming copper acetylide $\mathbf{1 2}$, which then reacts with the organic azide $\mathbf{9}$ in two possible ways, either directly, giving intermediate 15, or via a stepwise route (dashed arrows in Scheme 5) in which intermediates $\mathbf{1 3}$ and $\mathbf{1 4}$ are involved (Scheme 5c). Finally, intermediate $\mathbf{1 5}$ undergoes a reductive elimination step, providing the 1,4-disubstituted-1,2,3-triazoles $\mathbf{1 0}$ as product and regenerating the $\mathrm{Cu}(\mathrm{I})$ catalyst. 
a) Fokin, Sharpless and co-workers (2002)

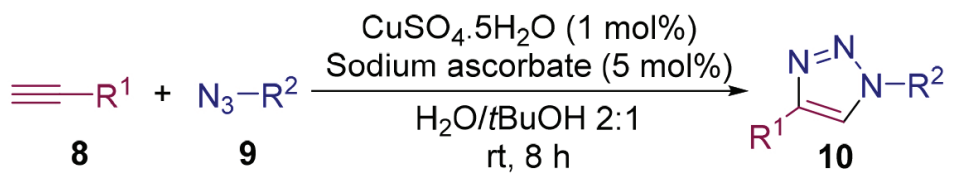

b) Selected examples

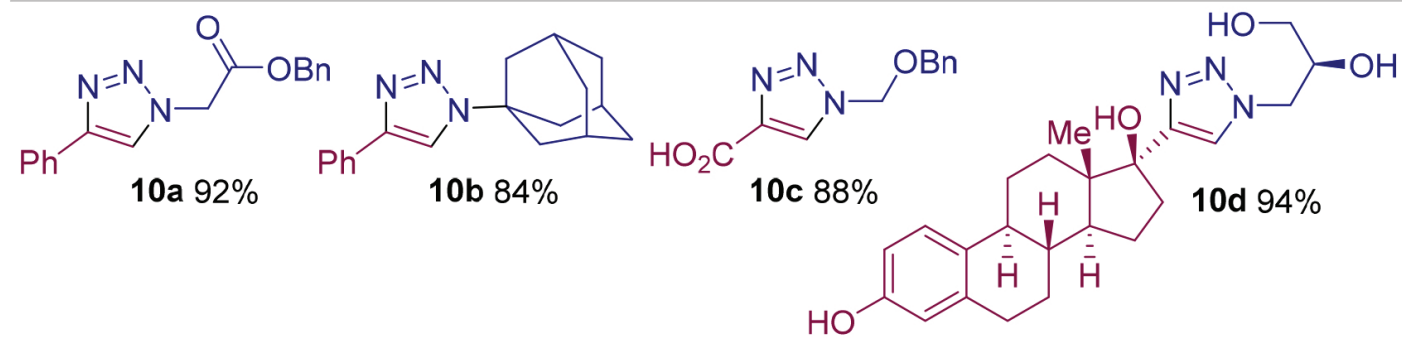

\section{c) Proposed mechanism}

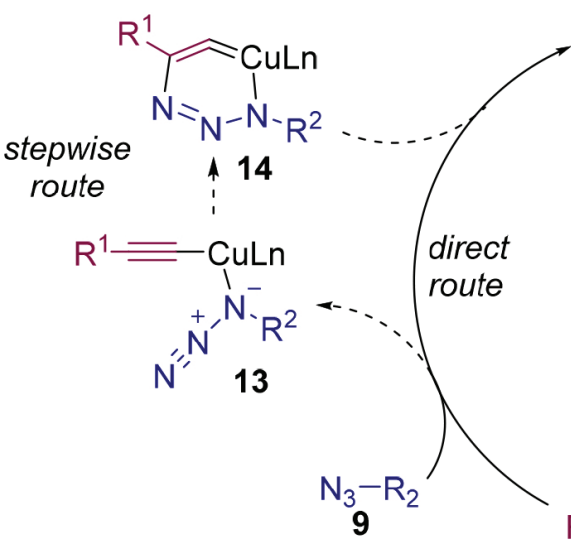

12
[CuLn]+

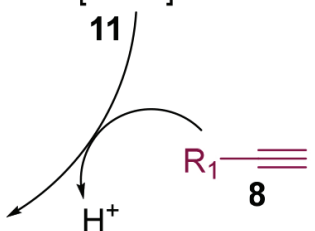

Scheme 5. Catalytic cycle for the formation of 1,4-disubstituted-1,2,3-triazoles

Later in 2005, Fokin, Finn and co-workers proposed a mechanism using DFT calculations, which was later corroborated by experimental evidences observed by several research groups. ${ }^{28}$ The mechanism starts in a similar way to the previously proposed one, where the copper species interacts with the alkyne $\mathbf{8}$ to form $\mathbf{1 6}$ (Scheme 6). On the other hand, in this case a second copper ion coordinates with 16, giving copper-coordinated acetylide 17 , which next reacts with the azide partner in a 1,3-dipolar cycloaddition fashion, leading to 6-membered di-copper intermediate 18. Subsequently, the rearrangement of $\mathbf{1 8}$ accompanied by the elimination of a copper species produces copper-triazole 19, which upon elimination of a second copper species furnishes product $\mathbf{1 0}$.

The use of copper catalysts successfully enabled the selective synthesis of 1,4-disubstituted 1,2,3-triazoles, categorically solving the regioselectivity issues of 1,3-dipolar cycloaddition reactions. On the other hand, some limitations were still associated with this approach, namely the impossibility of obtaining the 1,5-isomer and the restriction to the use of terminal alkynes rather that the internal ones. Considering such drawbacks, Fokin, Jia and co-workers reported in 2005 the development of a ruthenium-catalyzed approach that allowed the selective synthesis of 1,5-disubstituted-1,2,3-triazoles (Scheme 7). ${ }^{29}$ Interestingly, the ligands present in the ruthenium complex are of crucial importance for the regioselectivity, since $\mathrm{Ru}(\mathrm{OAc})_{2}\left(\mathrm{PPh}_{3}\right)_{2}$ led to the 1,4-isomer, while $\mathrm{CpRuCl}\left(\mathrm{PPh}_{3}\right)_{2}$ led to a mixture of 1,5- and 1,4-isomers in a 85:15 ratio and its methylated

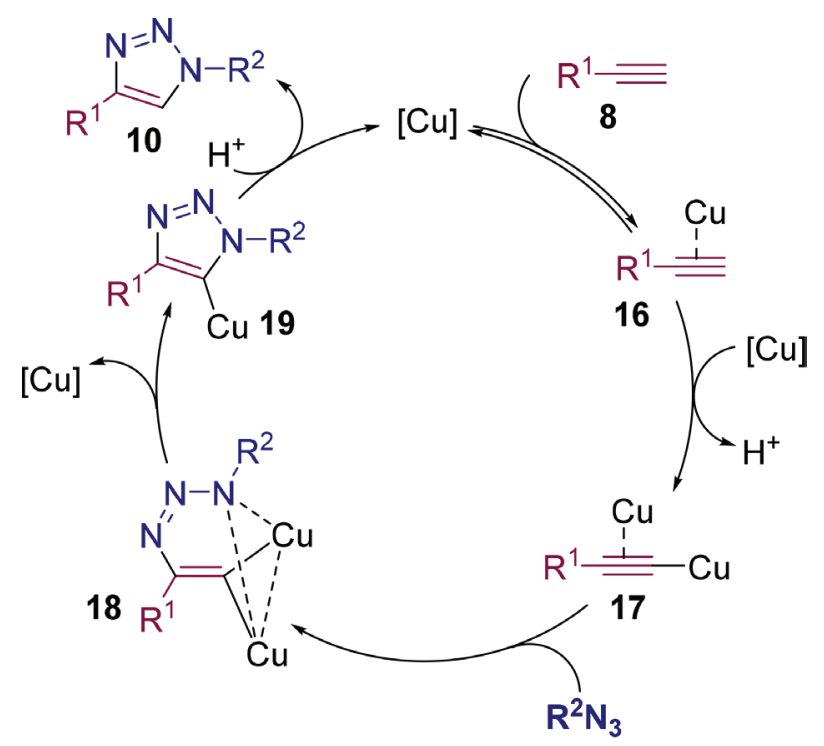

Scheme 6. Alternative catalytic cycle for the copper-catalyzed formation of 1,4-disubstituted-1,2,3-triazoles

version, $\mathrm{Cp} * \mathrm{RuCl}\left(\mathrm{PPh}_{3}\right)_{2}$, afforded exclusively the 1,5-isomer. The developed protocol was successfully applied to a wide range of azides and alkynes, with good to excellent yields of the 1,5-product 
being observed (Scheme 7b, 80-94\%). Importantly, internal alkyne diphenylacetylene has also shown to be reactive towards benzyl azide under the same conditions, giving the corresponding 1,4,5-trisubstituted-1,2,3-triazole as product (20e, Scheme 7b). In the proposed mechanistic cycle, both the azide and alkyne partners initially displace the triphenylphosphine ligands and coordinate with the ruthenium complex, giving intermediate 21, which after an intramolecular oxidative coupling step, furnishes six-membered ruthenacycle 22 (Scheme 7c). Next, 22 undergoes reductive elimination to give Ru-functionalized triazole $\mathbf{2 3}$, and finally the product $\mathbf{2 0}$ after the restoration of the catalyst.

In this sense, the consolidation of the methods for the preparation of 1,4-, 1,5- and 1,4,5-di/trisubstituted-1,2,3-triazoles has paved the path for the synthesis of several types of molecules. Guimarães and co-workers, for instance, reported the synthesis of four series of naphthoquinone-triazole hybrids with pronounced biological activity using a copper-catalyzed alkyne-azide 1,3-DC reaction as the key step (Scheme 8). ${ }^{30}$ The first group of hybrids, the 1,4-napthoquinone-1,2,3-trizoles 26, were obtained from the reaction of 2-bromo-1,4-naphthoquinone $\mathbf{2 4}$ with sodium azide, giving 2-azido-1,4-naphthoquinone $\mathbf{2 5}$, followed by a $\mathrm{CuAAC}$ reaction with a variety of alkynes (Scheme $8 \mathrm{a}$ ). In a similar fashion, lapachol 27 was converted to 3 -azido-nor- $\beta$-lapachone $\mathbf{2 8}$ after 4 reaction steps, and this molecule underwent a CuAAC with several alkynes to furnish nor- $\beta$-lapachone-1,2,3-triazoles 29 (Scheme 8b). Correspondingly, lapachol was used in the synthesis of $\alpha$-lapachone1,2,3-triazole hybrids $\mathbf{3 1}$ via 4-azido- $\alpha$-lapachones $\mathbf{3 0}$ (Scheme $8 \mathrm{c}$ ), while nor-lapachol gave nor- $\alpha$-lapachone-1,2,3-triazoles 34 via azido-nor- $\alpha$-lapachone intermediates 33 (Scheme $8 \mathrm{~d}$ ).

Besides copper and ruthenium, other metals have also been used as catalysts in the 1,3-dipolar cycloaddition reactions. For instance, Liao and co-workers reported in 2017 the use of rhodium as a catalyst in the 1,3-dipolar cycloaddition between internal ynamides 35 and azides 9 (Scheme 9). ${ }^{31}$ Over 30 compounds were synthesized in moderate to excellent yields (17 - 98\%), with benzyl azides furnishing considerably superior yields to the phenyl-substituted ones (Scheme 9b). Importantly, the reaction was not sensitive to moisture or air, and could be performed in a variety of solvents, including aqueous medium. The group has also performed DFT calculations in order to propose a mechanism for this regioselective cycloaddition (Scheme 9c). Initially, the oxidative coupling between the azide 9 and alkyne $\mathbf{3 5}$ takes place via transition state $\mathbf{3 8}$ to give the metallobicyclic $\mathrm{Rh}$-carbene intermediate 39, which is then isomerized to $\mathbf{4 0}$. Next, the reductive elimination via transition state $\mathbf{4 1}$ leads to the triazole catalyst-coordinated complex $\mathbf{4 2}$.

Recently, Zeng and co-workers reported the use of an iridium complex to promote the reaction between 1-alkynyltriazenes $\mathbf{4 3}$ and benzyl azide $\mathbf{4 4}$ as a direct approach towards functionalized 1,4,5-trisubstituted-1,2,3-triazoles 45 (Scheme 10). ${ }^{32}$ The use of triazene-functionalized alkynes is highly advantageous, since the triazene moiety can act as a directing group, and also may be transformed into a range of other functional groups. Using an [ $\operatorname{Ir}(\mathrm{cod})$ $\mathrm{Cl}]_{2}$ complex as catalyst, several functionalized products could be synthesized in good to excellent yields (Scheme 10b, 27-98\%).

a) Fokin, Jia and co-workers (2005)

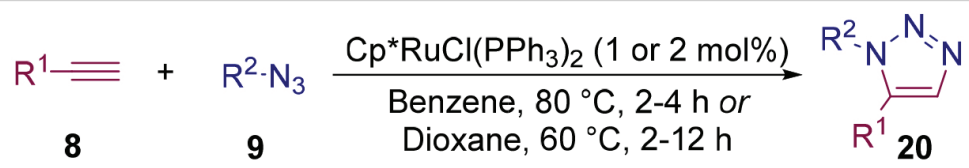

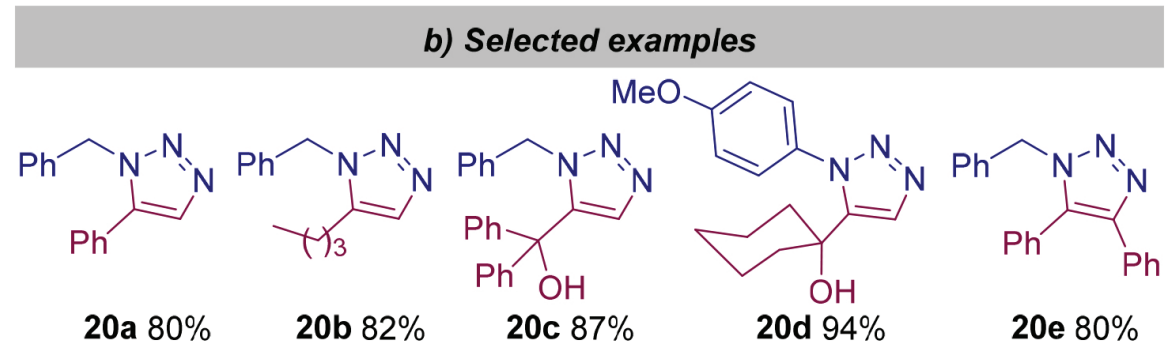

c) Proposed mechanism

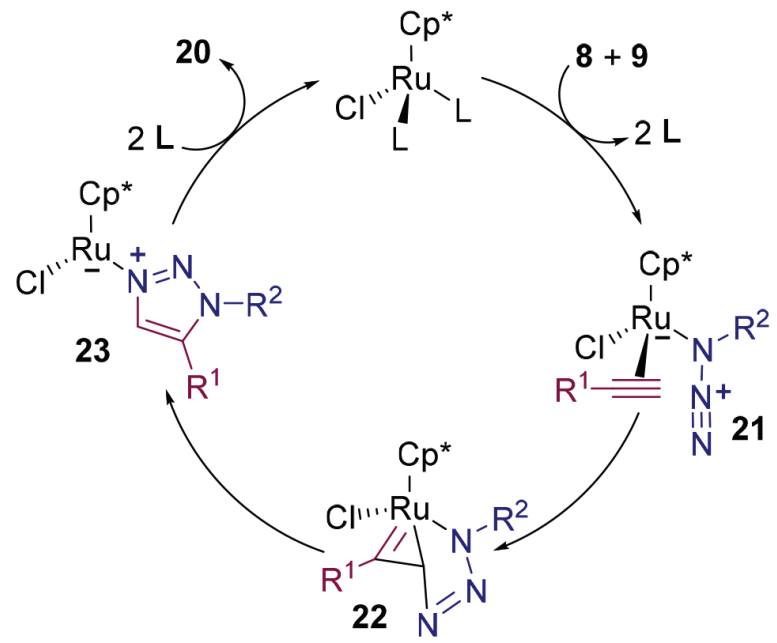

Scheme 7. Synthesis of 1,5-disubstituted-1,2,3-triazoles using $C p^{*} R u C l\left(P P h_{3}\right)_{2}$ as catalyst 
a) 1,4-Naphthoquinone-1,2,3-triazole hybrids

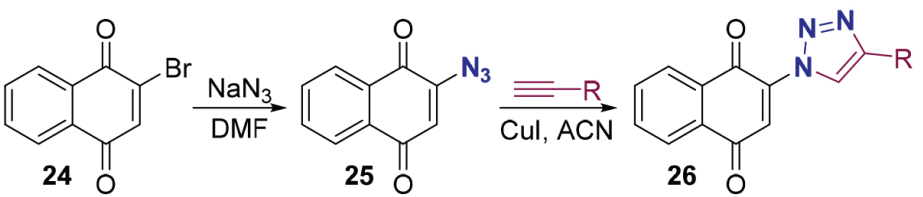

$\mathbf{R}=\mathrm{CH}_{2} \mathrm{OH}, \mathrm{CH}_{2} \mathrm{NPhth}, \mathrm{Ph}, 4-\mathrm{OMeC}_{6} \mathrm{H}_{4}, 4-\mathrm{BrC}_{6} \mathrm{H}_{4}, 4-\mathrm{NO}_{2} \mathrm{C}_{6} \mathrm{H}_{4}, 4-\mathrm{MeC}_{6} \mathrm{H}_{4}$

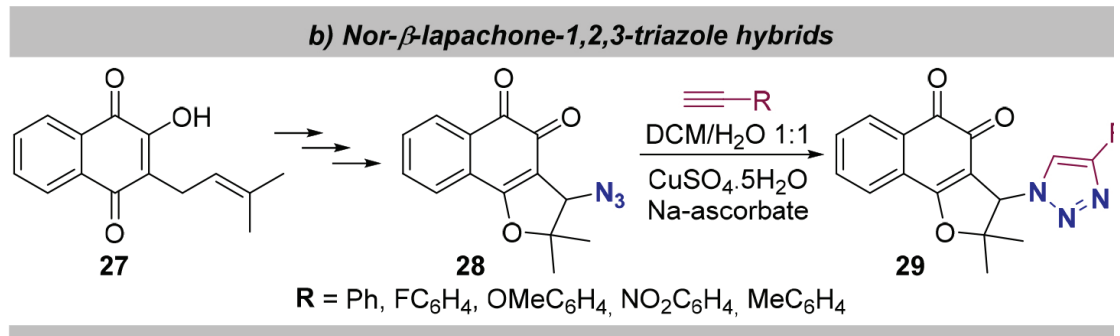

c) $\alpha$-Lapachone-1,2,3-triazole hybrids

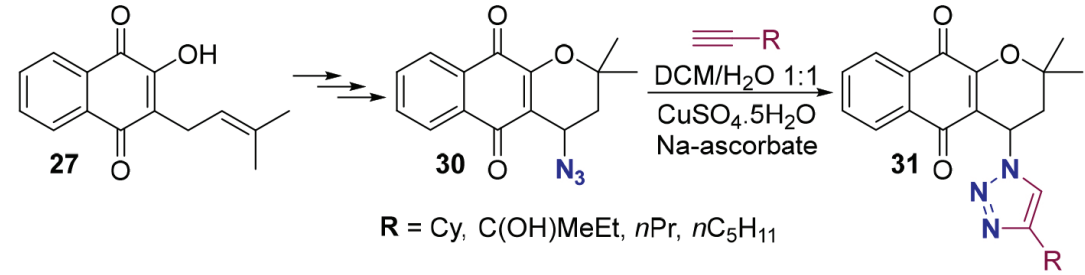

d) Nor- $\alpha$-Lapachone-1,2,3-triazole hybrids

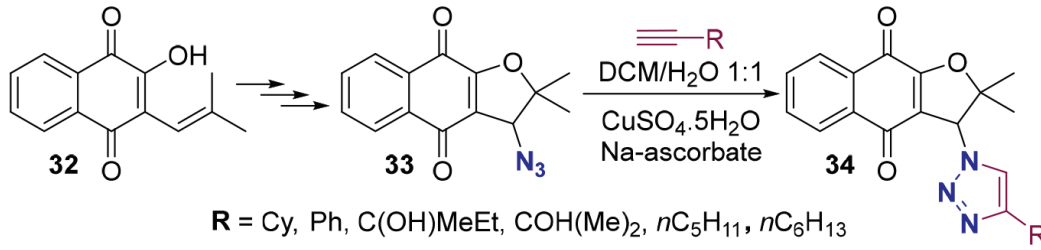

Scheme 8. Synthesis of several naphthoquinone-1,2,3-triazole hybrids with promising biological activity using CuAAC as the key step

a) Li, Huang and co-workers (2017)

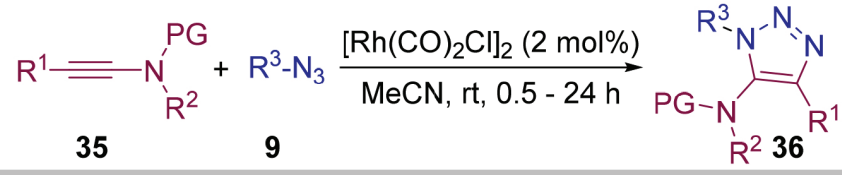

b) Selected examples

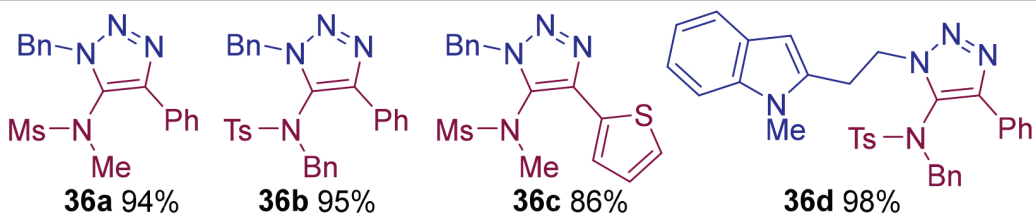

c) Proposed mechanism
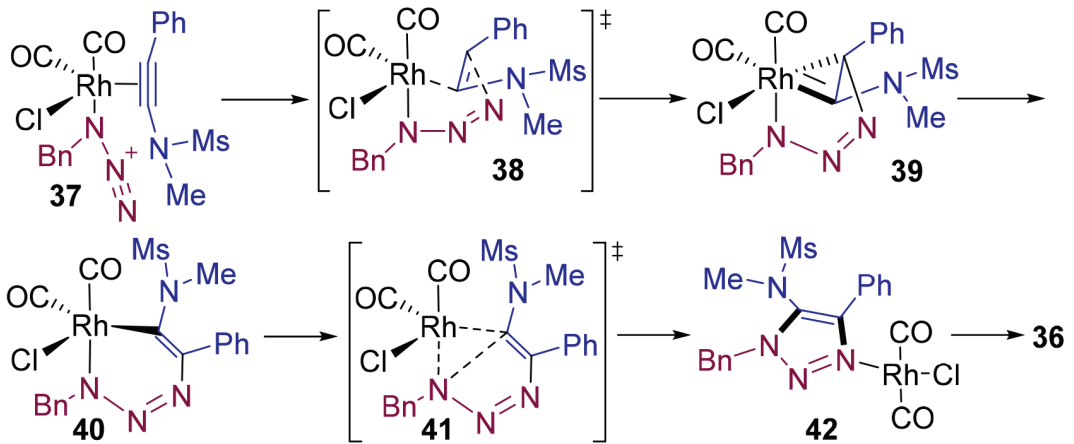
a) Cui and co-workers (2020)

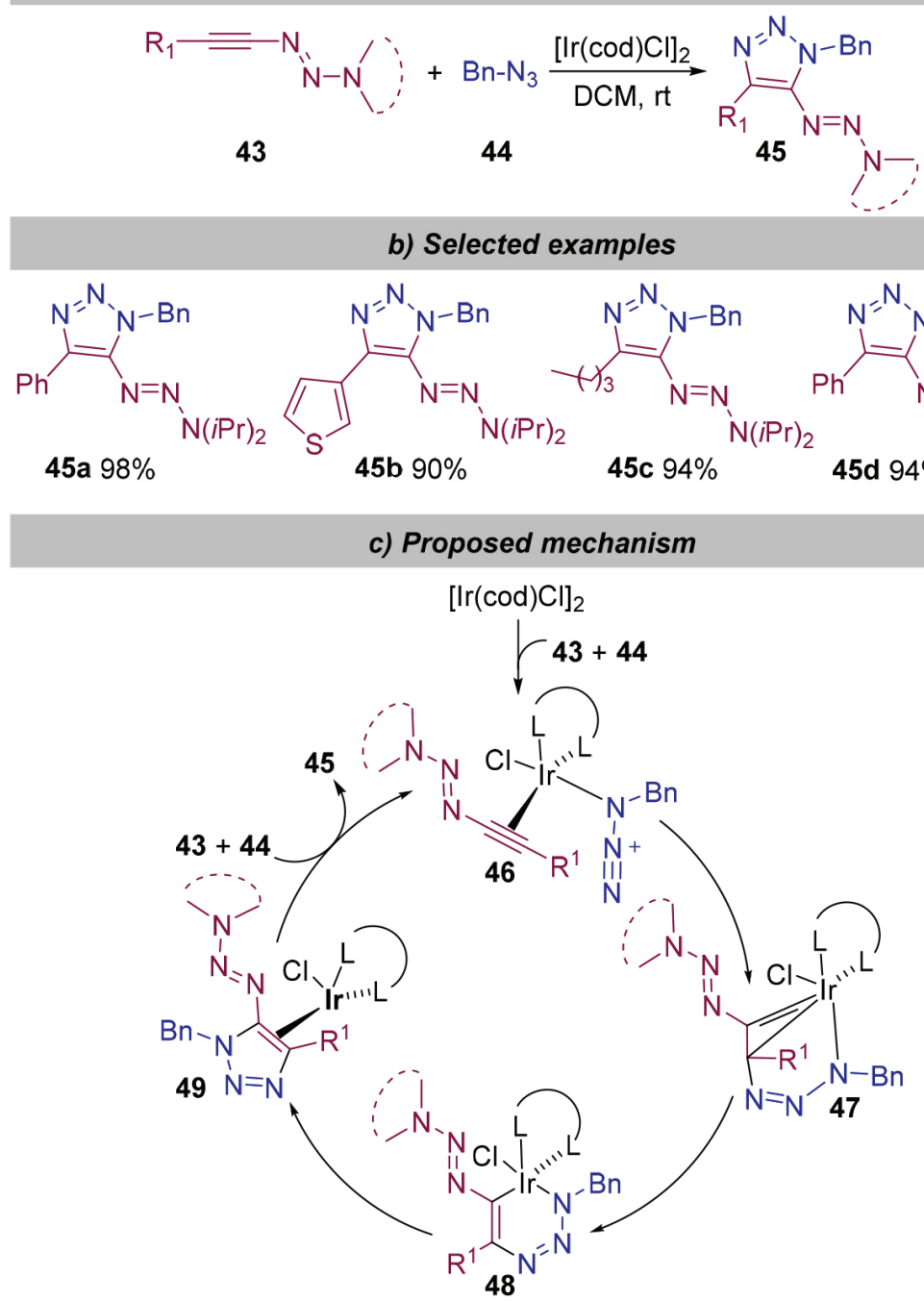

Scheme 10. Iridium-catalyzed cycloaddition between 1-alkynyltriazenes and benzyl azide for the synthesis of functionalized 1,4,5-trisubstituted-1,2,3-triazoles 51

The proposed mechanism is similar to that of ruthenium, involving the initial coordination of both partners, giving intermediate 46, which after intramolecular oxidative addition leads to the sixmembered iridacycle 47 (Scheme 10c). Next, 47 isomerizes to $\mathbf{4 8}$, which furnishes $\mathbf{4 9}$ after a reductive elimination step. Finally, the complexation of $\mathbf{4 3}$ and $\mathbf{4 4}$ releases product $\mathbf{4 5}$ and regenerates the $\operatorname{Ir}(\mathrm{I})$ species 46, reestablishing the catalytic cycle.

Although the thermal and metal-catalyzed 1,3-dipolar cycloaddition between azides and alkynes has proved to be a versatile method for the synthesis of 1,2,3-triazoles, finding increasing applications in polymer science, materials chemistry, and pharmaceuticals, among others, its applications in biological systems are somewhat limited. Considering these facts, Agard and co-workers described in 2004 the development of a room temperature metal-free approach for the synthesis of 1,2,3-triazoles that relies on the pronounced bond angle deformation of cyclooctines when compared to unstrained alkynes, which provides a dramatic reaction rate acceleration (Scheme 11). ${ }^{33}$ In this sense, when cyclooctine derivative $\mathbf{5 0}$ reacts with azides, the two regioisomers of triazole 51 are formed in approximately equal amounts. This approach was used in the functionalization of living cells with no apparent toxicity. For that, biotinylated cyclooctyne $\mathbf{5 7}$ was synthesized via the silver perchlorate-promoted electrocyclic ring opening of $\mathbf{5 2}$ to give the corresponding trans-allylic cation, which was promptly reacted with methyl 4-(hydroxymethyl)-benzoate $\mathbf{5 3}$ to furnish bromo-trans-cyclooctene $\mathbf{5 4}$ (Scheme 11b). Next, the base-mediated elimination of the vinyl bromide moiety followed by saponification leads to intermediate $\mathbf{5 5}$, which was coupled to biotin analogue $\mathbf{5 6}$ to afford 57. Then, Jurkat cells were functionalized with $\mathrm{N}$-azidoacetyl sialic acid and reacted with $\mathbf{5 7}$ at room temperature; remarkably, the azide-functionalized cells displayed a dose-dependent increase in fluorescence upon treatment with the cyclooctyne probe $\mathbf{5 7}$.

The synthesis of 1,2,3-triazoles can also be achieved using other dipolarophiles than alkynes, for instance alkenes. In this case, however, a triazoline is obtained as product, and a subsequent elimination or oxidation reaction leads to the triazole product. Stevens and co-workers, for instance, described the use of enol ethers $\mathbf{5 8}$ as partners in cycloaddition reactions with azides, giving intermediate 59, which affords the product $\mathbf{6 0}$ after an elimination step (Scheme 12). By using this approach, several 1,4-disubstituted1,2,3-triazoles $\mathbf{6 0}$ could be synthesized with moderate to good yields (49-78\%) under solvent-free conditions (Scheme 12b). ${ }^{34}$

Another important work in this field was disclosed by Amantini and co-workers in 2005, which employed electron-deficient olefins $\mathbf{6 1}$ as dipolarophiles and trimethylsilyl azide $\mathbf{6 2}$ in the presence of TBAF, obtaining 4-aryl-5-cyano- or 4-aryl-5-carbethoxy-1H-1,2,3triazoles 63 as products (Scheme 13). ${ }^{35}$ In this case, a triazoline-type intermediate is also initially formed and converted to the desired 


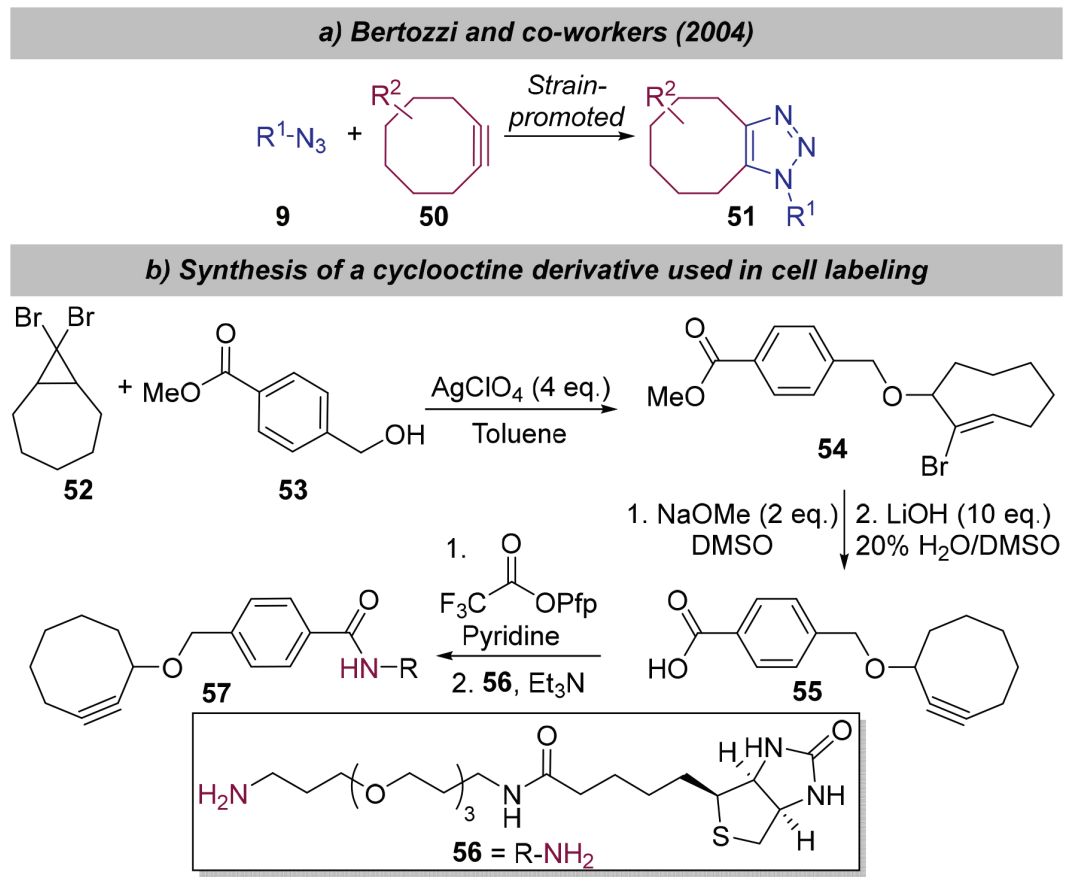

Scheme 11. Strain-promoted 1,3-dipolar cycloaddition between azides and cyclooctine derivatives

\section{a) Stevens and co-workers (2005)}

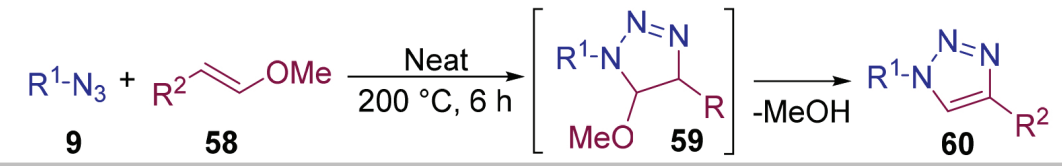

b) Selected examples

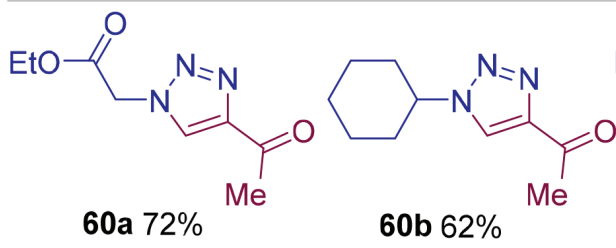<smiles>CC(=O)c1nnn(C2CCCCC2)c1C</smiles>

Scheme 12. Preparation of 1,2,3-triazoles 60 from enols ethers and azides

products upon elimination of $\mathrm{HNO}_{2}$; several products were prepared with yields ranging from 70 to $90 \%$ (Scheme 13b).

1,4-Naphthoquinones may also be used as electron-deficient alkenes in the synthesis of 1,2,3-triazoles. Campos and co-workers reported the use of such scaffolds in the presence of glycosyl azides aiming the synthesis of fused naphthotriazole derivatives via a thermal [3+2] cycloaddition reaction (Scheme 14). ${ }^{36}$ Natural glycosylconjugated compounds are useful drugs commonly used clinically in the treatment of cancer, the carbohydrate residues in these structures being important for their solubilization, as well as for decreasing their toxicity and improving their pharmacokinetic properties. ${ }^{37,38}$ A possible mechanism for this transformation involves an initial 1,3-DC reaction between $\mathbf{6 4}$ and the glycosyl azides, producing the corresponding triazoline intermediates $\mathbf{6 5} \mathbf{a}$, which are tautomerized to $\mathbf{6 5 b}$ and further oxidized to form the glycotriazole derivatives $\mathbf{6 6}$.

In some cases, organic and inorganic bases may be used to activate the dipolarophile and promote the reaction. An interesting example of such approach is the work published by Singh and co-workers, who developed the DBU-catalyzed synthesis of fused 1,2,3-triazoles $\mathbf{6 8}$ from the cycloaddition of various aryl azides with cyclic 1,3-dicarbonyl compounds 67 in PEG-400 (Scheme 15). ${ }^{39}$ This metal-free procedure enabled the synthesis of a series of fused 1,2,3-triazoles (78-92\%) using readily available starting materials in a short reaction time (Scheme 15b). Additionally, the possibility of recycling both the catalyst and the solvent are major advantages of this approach. In the proposed mechanism, DBU initially deprotonates the 1,3-dicarbonyl compound 67, giving ion pair intermediate 69, which undergoes a cycloaddition step with the azide partner, furnishing $\mathbf{7 0}$ (Scheme 15c). Next, 70 is protonated by the $\mathrm{HDBU}^{+}$species, giving triazoline 71. Finally, the elimination of a water molecule from $\mathbf{7 1}$ gives rise to product $\mathbf{6 8}$.

Another interesting method for the synthesis of fused triazoles was reported in 2019 by Duan and co-workers, who described a novel palladium-catalyzed three-component approach using allenynes $\mathbf{7 2}$, aryl or alkenyl iodides $\mathbf{7 3}$, and sodium azide for the synthesis of bicyclic 1,2,3-triazoles 74 (Scheme 16). Over 20 examples were reported using this protocol, with moderate to good yields (Scheme 16b, 38-79\%). On the other hand, when an allenyne bearing a carbon atom attached to two ester groups in place of $\mathrm{N}$-Ts was used, the corresponding desired product was not formed. Based on a series of control experiments, the authors proposed a mechanism in which the oxidative addition of the aryl iodide $\mathbf{7 3}$ to the $\mathrm{Pd}(0)$ catalyst initially takes place, giving intermediate 75 (Scheme 16c). Next, 75 undergoes insertion with 
the allene compound $\mathbf{7 2}$, leading to ( $\pi$-allyl)palladium intermediate 76, which is then attacked by the azide anion, giving interconvertible 77a and 77b (via a Winstein allylic azide rearrangement) as intermediates. Finally, an intramolecular cycloaddition furnishes fused 1,2,3-triazoles $\mathbf{7 4} .^{40}$

A substantially more complex $1,3-\mathrm{DC}$ is the reaction of ethyl cyanide with aryl azides, in which a cyclization involving the nitrile group takes place. This reaction is an important approach towards the preparation of 5-amino-1,2,3-triazoles and was studied by Otto Dimroth. ${ }^{41,42}$ Dimroth observed a rearrangement of the nitrogen atoms in the structure that led to the conversion of 1,2,3-triazoles into other isomeric 1,2,3-triazoles with different atom connections. As shown in Scheme 17, the initial deprotonation of nitrile $\mathbf{7 8}$ gives active anionic dipolarophile 79, which undergoes a cycloaddition reaction with phenylazide to furnish imine triazole $\mathbf{8 0}$, and $\mathbf{8 1}$ is then formed upon tautomeric equilibrium. The ratio of different 1,2,3-triazole compounds in the equilibrium is temperature-dependent, and their interconversion is proposed to occur via open intermediate $\mathbf{8 2}$ upon reaction with water. The mechanism of DR may be explained via the closure of diazoimine intermediates $(\mathbf{8 4}$ and $\mathbf{8 5})$ to furnish the triazole compounds $(\mathbf{8 1}$ or $\mathbf{8 3}$, Scheme 17). ${ }^{43-}$ It is important to highlight that in the last decades the Dimroth rearrangement has become an important reaction in organic synthesis, allowing the preparation of new substances that are not easily rationalized via retrosynthetic analyses. ${ }^{46,47}$

Another important type of dipoles are nitrilimines, which can be generated in situ via the base-promoted dehydrohalogenation of the corresponding hydrazonoyl halides. The 1,3-dipolar cycloaddition reaction of such compounds with alkynes, alkenes, and $\mathrm{C}=\mathrm{N}$ bondcontaining compounds provide a simple method for the construction of substituted pyrazoles, pyrazolines and 1,2,4-triazoles.

Recently in 2020, Huang and co-workers developed a methodology involving regioselective 1,3-DC of nitrilimines $\mathbf{8 8}$ generated in situ from the reaction between ( $Z$ )- $N$-aryl-2-oxopropanehydrazonoyl bromide 87 and $\mathrm{Et}_{3} \mathrm{~N}$ with 3-arylpyrrolo[1,2-a]pyrazines 86, affording 1-(1,5-diaryl-1,10b-dihydropyrrolo[1,2-a][1,2,4]triazolo[3,4-c] pyrazin-3-yl)ethanones 89 (Scheme 18) ${ }^{48}$ Several 3-arylpyrrolo[1,2-a pyrazines 89 were successfully employed in this protocol, giving products 89 in moderate yields (61-79\%, Scheme $18 \mathrm{~b})$.

\section{Synthesis of Pyrazole/Tetrazole Derivatives}

Undoubtedly, azides are the mostly used dipole partner in 1,3-dipolar cycloaddition reactions. However, several other dipoles have also been explored in this reaction, leading to high structural diversity. Azomethine imines, for instance, are 1,3-dipoles of the allylic type and present two type of resonance structures, iminium imide and diazonium ylide. Such compounds are readily accessible and stable, and have been observed as intermediates in the synthesis of different di-nitrogenated heterocycles through 1,3-DC under thermal or catalyzed conditions. ${ }^{49}$

The 1,3-DC reaction of azomethine imines with alkynes has been widely employed in the last decades as an efficient strategy for the preparation of important $N$-heterocyclic compounds. Fu and co-workers, for example, published back in 2003 one of the seminal works in this field, which described the enantioselective reaction between azomethine imines $\mathbf{9 0}$ and terminal alkynes $\mathbf{8}$, leading to the $N, N$ '-bicyclic pyrazolidinone products 91 (Scheme 19a). ${ }^{50}$ In recent years, several important works have been reported involving this type of dipole, e.g. the 1,3-DC between isatin $N, N^{\prime}-$ cyclic azomethine imine $\mathbf{9 2}$ and maleimides $\mathbf{9 3}$, which gave the interesting spirooxindole scaffolds $\mathbf{9 4}$ as products rather than the expected corresponding pyrazolidinones, as described by Wang and co-workers in 2017 (Scheme 19b). ${ }^{51}$ Recently in 2020, the reactivity of isatin $N, N$ '-cyclic azomethine imines $\mathbf{9 2}$ was once again probed,

a) Fringuelli, Vaccaro and co-workers (2005)
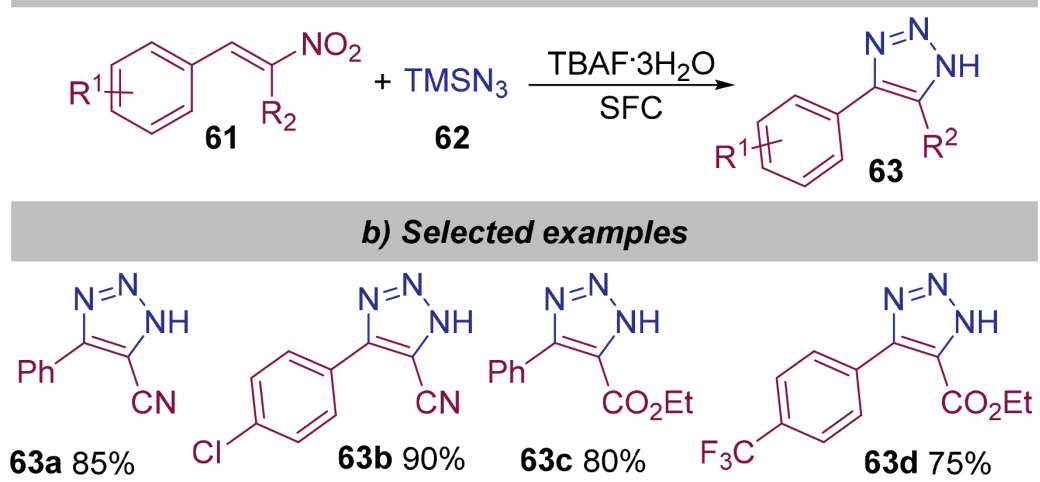

Scheme 13. Synthesis of substituted 1,2,3-triazoles 46 through TBAF-catalyzed 1,3-DC

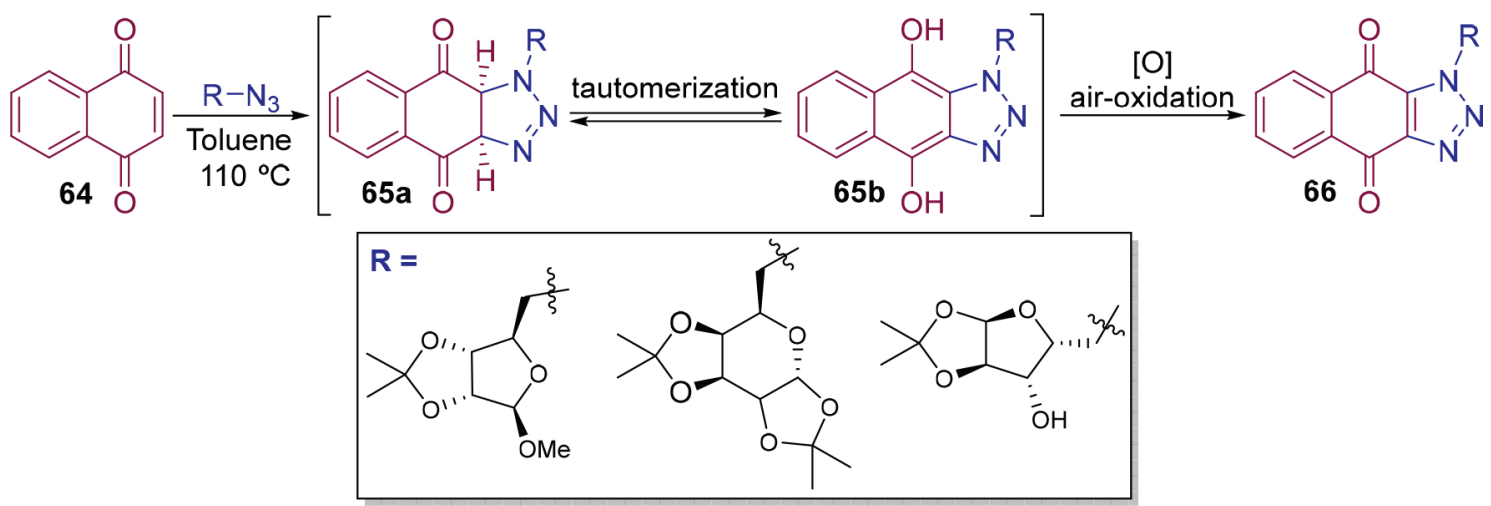



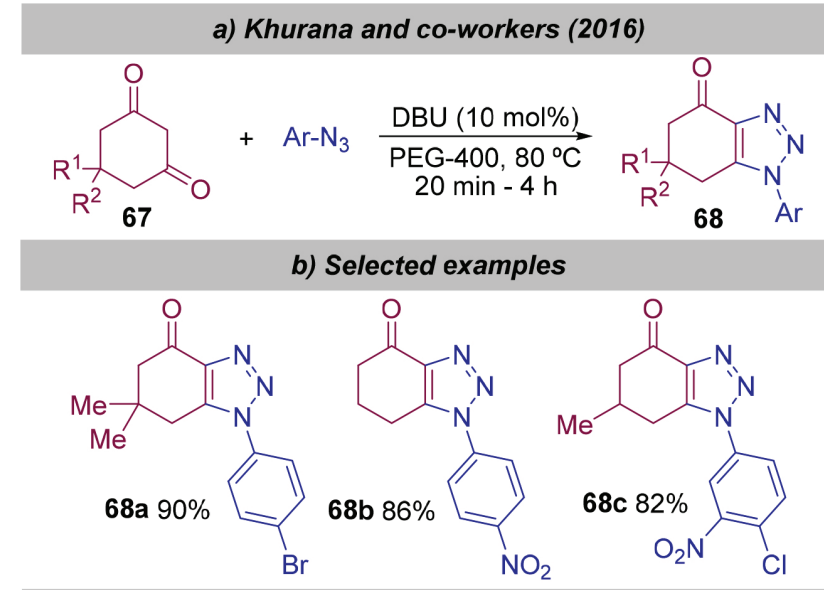

c) Proposed mechanism
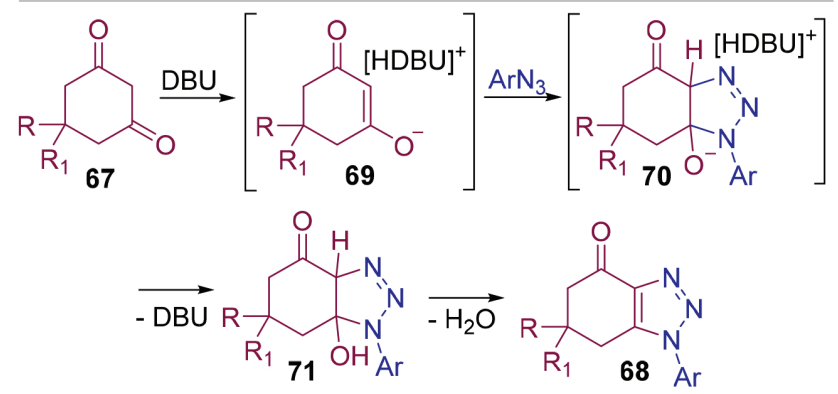

Scheme 15. DBU-catalyzed synthesis of fused 1,2,3-triazoles 51 from cyclic 1,3-dicarbonyl compounds and organic azides

\section{a) Ma and co-workers (2019)}

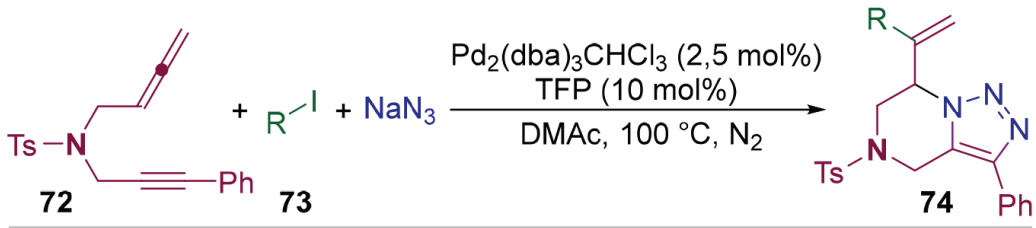

b) Selected examples

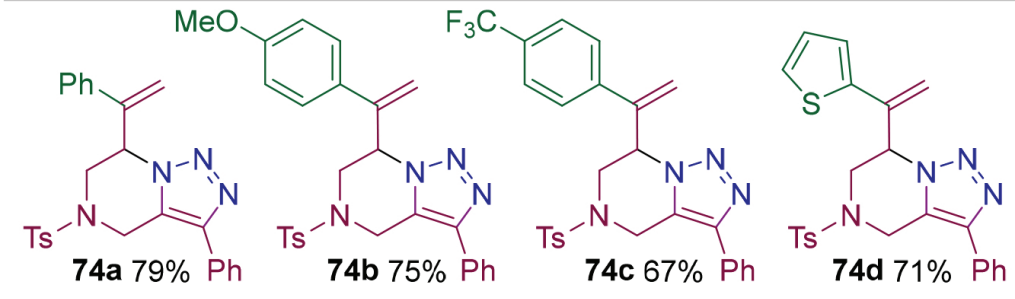

\section{c) Proposed mechanism}
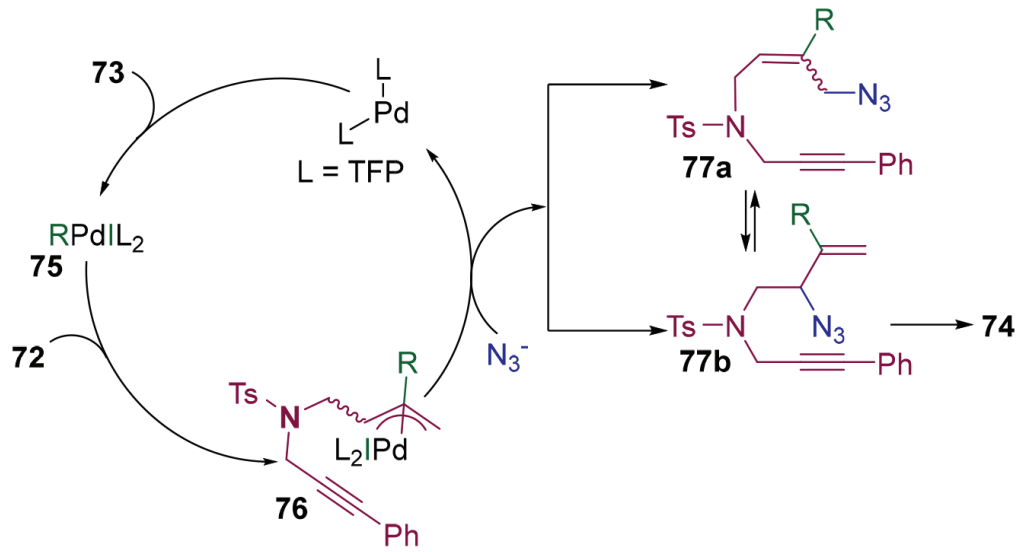


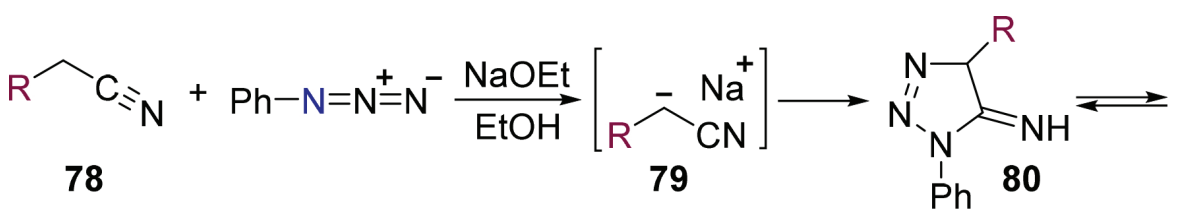<smiles>[R]C(/N=N/O)=C(/N)Nc1ccccc1</smiles><smiles>COCCO</smiles><smiles>[R]c1nnn([R3]([H])([H])[H])c1Nc1ccccc1</smiles><smiles>C=C</smiles><smiles>[R]C(=[N+]=[N-])/C(N)=N/c1ccccc1</smiles>

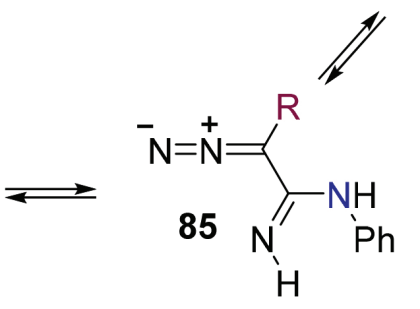

Scheme 17. 1,3-Dipolar cycloaddition reaction of ethyl cyanide with aryl azides followed by Dimroth rearrangement

\section{a) Li and co-workers (2020)}
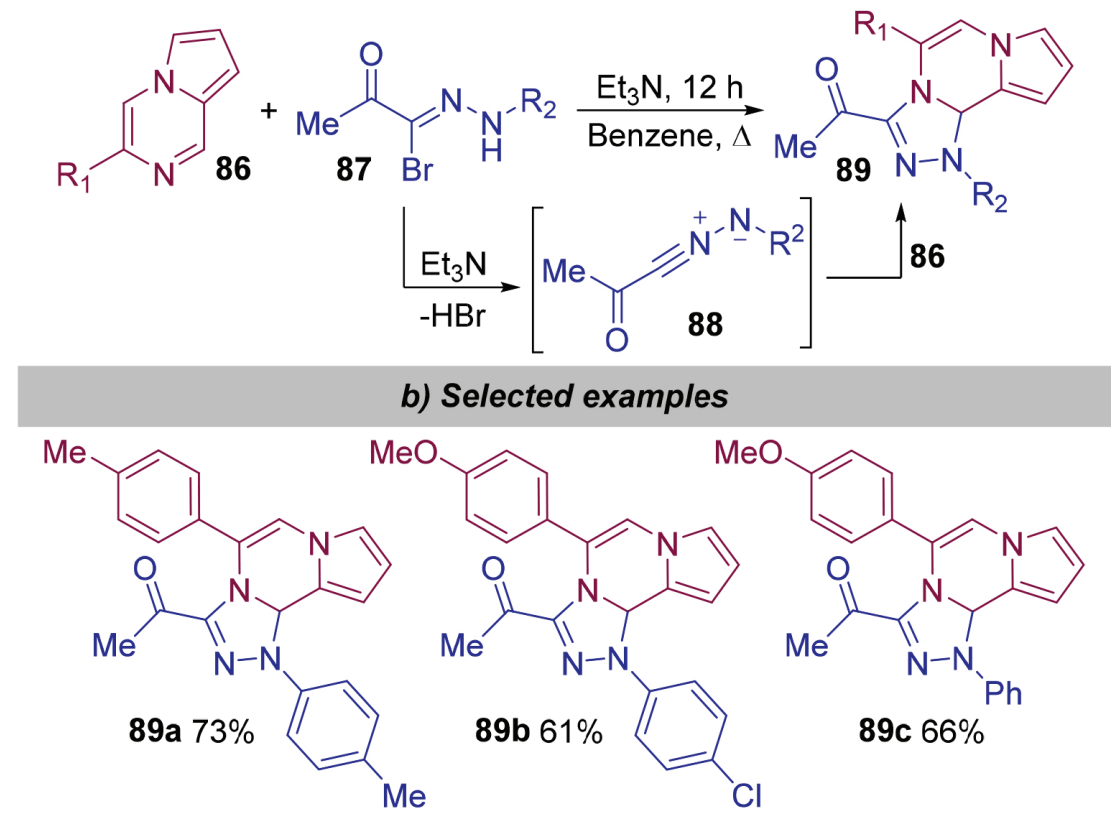

Scheme 18. Synthesis of 1-(1,5-diaryl-1,10bdihydropyrrolo [1,2-a][1,2,4]triazolo[3,4-c] pyrazin-3-yl) ethanones from 3-arylpyrrolo[1,2-a]pyrazines and nitrilimines

this time towards electron deficient alkynes 95, furnishing spiro pyrazolidinones 96 (Scheme 19c)..$^{52}$

In 2020, Tupychak and co-workers reported the synthesis of 5-aminopyrazoles 99 with high yields and regioselectivity employing the base-promoted 1,3-DC between hydrazonoyl chlorides 97 and propanenitriles 98 (Scheme 20).$^{53}$ In the proposed mechanism, the base initially abstracts the acidic hydrogen from both the hydrazonoyl chloride 97 and the propanenitriles 98 , giving 100 and 3-oxopropanenitrile enolate 101, respectively. In the next step, the enolate $\mathbf{1 0 1}$ attacks the electrophilic carbon of hydrazonoyl chloride, leading to the imine derivative $\mathbf{1 0 2}$, which is tautomerized to pyrazole 99 (Scheme 20c).
In the recent work published by Ramu and co-workers, a metal-free strategy was employed to synthesize pyrazolo[1,5-c] quinazolines $\mathbf{1 0 5}$ from 3-ylideneoxindoles $\mathbf{1 0 3}$ and tosyldiazomethane 104 (Scheme 21). ${ }^{54}$ In this case, an azomethine ylide was used as dipole. ${ }^{55,56}$ By employing potassium carbonate as a base, high yields and regioselectivities were observed. In this case, it was proposed that water initially reacts with diazo compound $\mathbf{1 0 4}$ giving intermediate $\mathbf{1 0 6}$ after elimination of the benzoate anion. Then, $\mathbf{1 0 6}$ undergoes a proton abstraction to form azomethine ylide species $\mathbf{1 0 7}$, which reacts with 3 -ylideneoxindole $\mathbf{1 0 3}$ in a 1,3-DC, giving spiro-compound 108. Next, a 1,3 H-shift occurs, leading to $\mathbf{1 0 9}$, followed by a ring expansion step, furnishing 110. Subsequently, a 1,5 H-shift gives 
a) Fu and co-workers (2003)
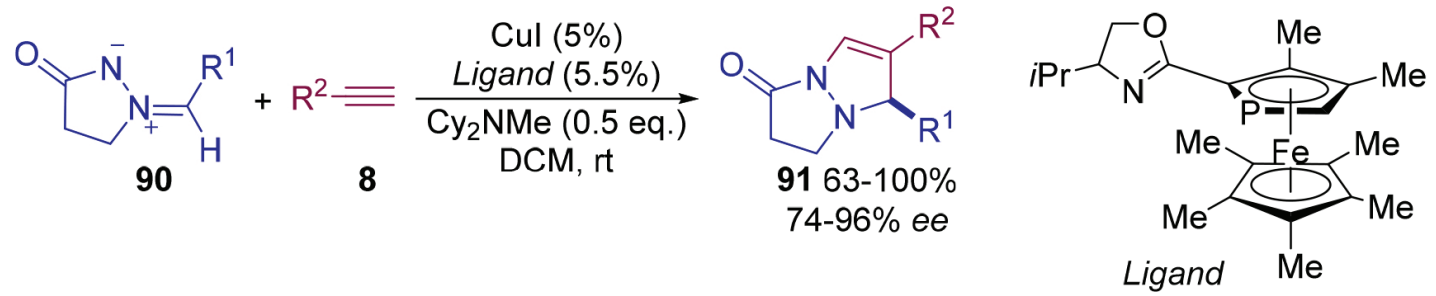

\section{b) Wang and co-workers (2017)}<smiles></smiles>

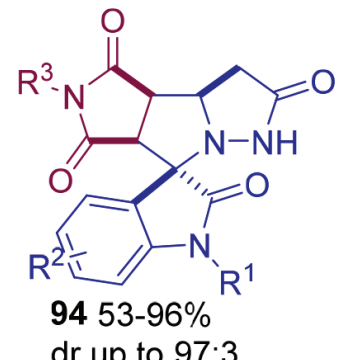

\section{c) Xing and co-workers (2020)}

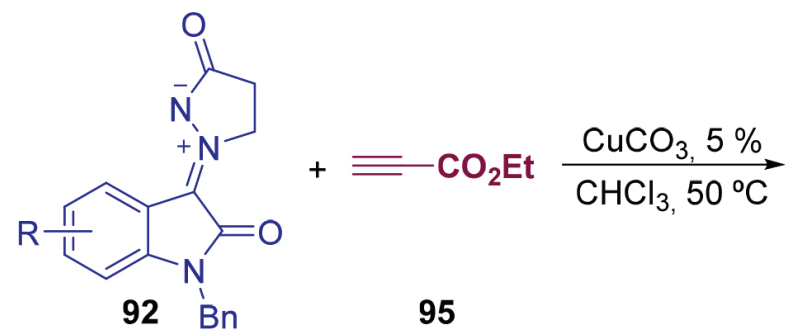

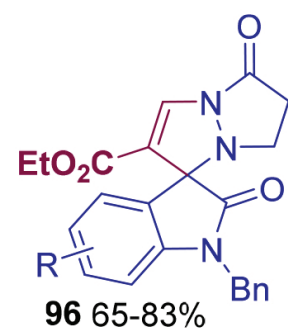

Scheme 19. 1,3-Dipolar cycloaddition reaction of azomethine imines with alkynes and maleimides

a) Tupychak and co-workers (2020)

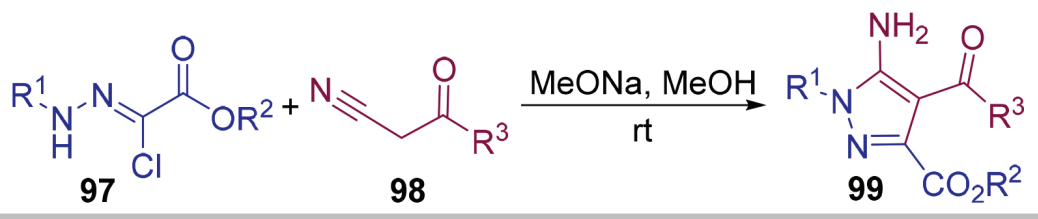

b) Selected examples<smiles>CCOC(=O)c1nn(-c2ccc(Cl)cc2)c(N)c1C(=O)c1cccn1C(=O)OCc1ccccc1</smiles>

\section{c) Proposed mechanism}

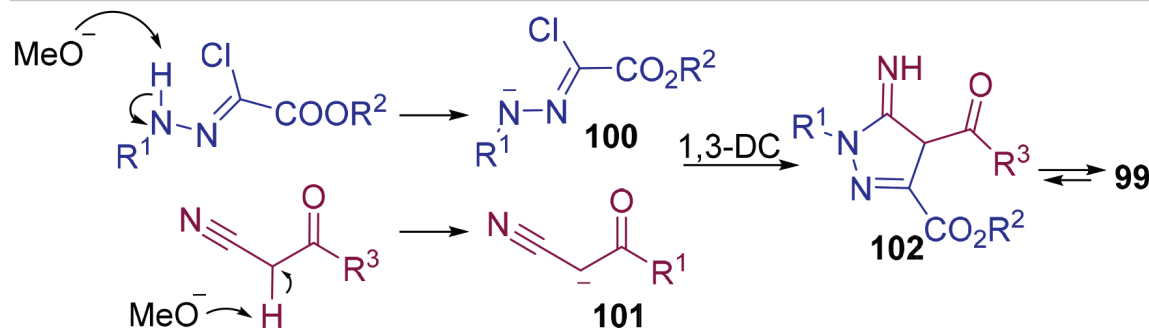


111, which is oxidized the pyrazolo[1,5-c]quinazoline 112. Finally, the elimination of the tosyl group from $\mathbf{1 1 2}$ gives rise to product $\mathbf{1 0 5}$ (Scheme 21b).

Another interesting example of 1,3-DC was reported in 2020 by Xiao and co-workers, who described the reaction between arenediazonium salts 113 and diazoacetates 114 under silver catalysis to furnish carboxylic tetrazoles 115 (Scheme 22). This straightforward approach was applicable to a wide range of diazoacetates functionalized with different groups, as well as to a variety of areniumdiazonium salts, leading to the corresponding products in moderate to excellent yields (Scheme 22b, 46-92\%). ${ }^{57}$

\section{Synthesis of Isooxazoline/Isoxazolidine and Oxadiazole Derivatives}

Nitrile oxides are another interesting class of 1,3-dipoles for 1,3$\mathrm{DC}$, having the potential of generating important $\mathrm{N}, \mathrm{O}$-heterocyclic compounds when reacted with different dipolarophiles. Similarly to the reaction between azides and alkynes, the thermal 1,3-DC between nitrile oxides and alkynes may require catalysts in order achieve good levels of regioselectivity.

As depicted in Scheme 23, the copper(I)- and $N$-heterocyclic carbene (NHC)-catalyzed 1,3-DC of nitrile oxide generates 3,5-disubstituted isoxazoles, while reactions catalyzed by ruthenium(II) result in the 3,4-disubstituted isoxazoles. ${ }^{58}$

The proposed mechanism for the $\mathrm{Cu}$ - and $\mathrm{Ru}$-promoted transformations are analogous to those of CuAAC. In the case of the $\mathrm{Ru}$-catalyzed reaction, both reagents $\mathbf{1 1 6}$ and $\mathbf{8}$ initially coordinate with the metal, giving intermediate $\mathbf{1 2 3}$, which next undergoes the formation of ruthenacycle 124, and subsequently 125 after an oxidative coupling, followed by the release of 3,4-disubstituted isoxazole 118 in the final step (Scheme 23b). In the NHCpromoted process, the treatment of imidazolium salt 119 with triethylamine $\left(\mathrm{Et}_{3} \mathrm{~N}\right)$ gives the $\mathrm{NHC}$ catalyst, which regioselectively adds to the alkyne, forming zwitterionic adduct 120 (Scheme 23b). Next, 120 adds to the nitrile oxide 116, giving zwitterionic species 121, which undergoes an oxygen hetero-cyclization step and releases 3,5-disubstituted isoxazole product 117 and the NHC catalyst.

The use of nitrile oxides is comparatively underdeveloped as a consequence of their high propensity to dimerize to the related furoxan, and so their generation in situ has become an alternative to overcome this issue. A recent example of this type of process is the work published by Ou and co-workers in 2019, which described the 1,3-DC between $\beta$-fluoroalkyl-vinyl 2-pyridylsulfones $\mathbf{1 2 6}$ and nitrile oxides formed from hydroxamoyl chlorides $\mathbf{1 2 7}$ to deliver isoxazoline

a) Babu and co-workers (2020)

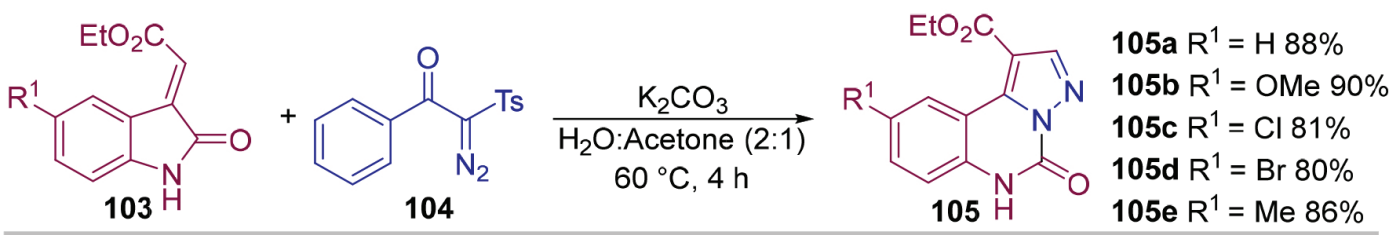

c) Proposed mechanism

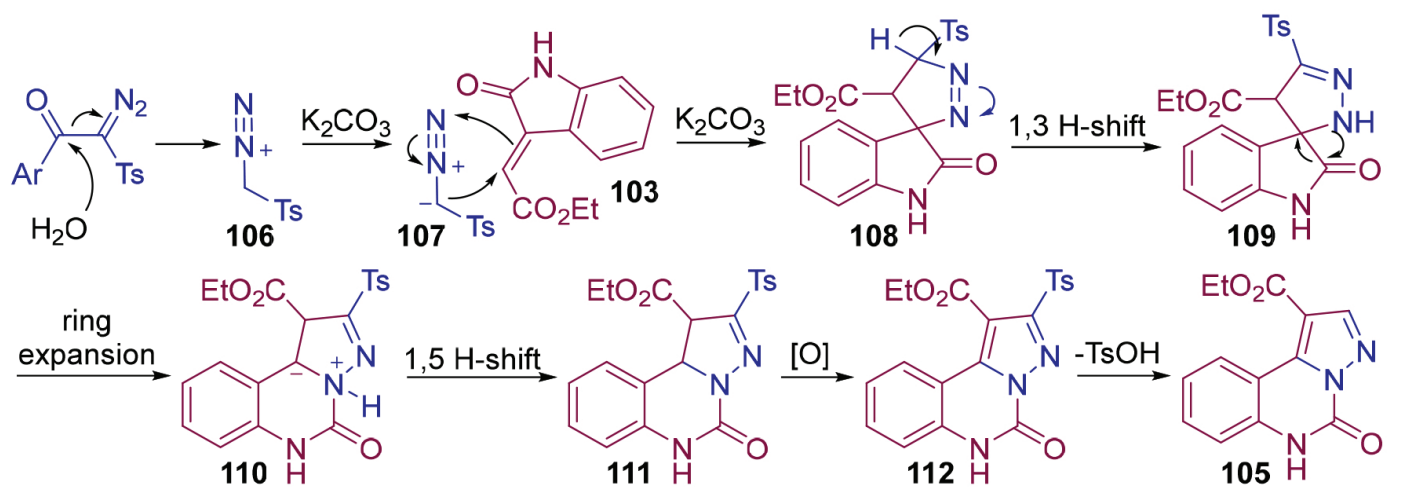

Scheme 21. Synthesis of pyrazolo [1,5-c]quinazolines from 3-ylideneoxindoles and tosyldiazomethane

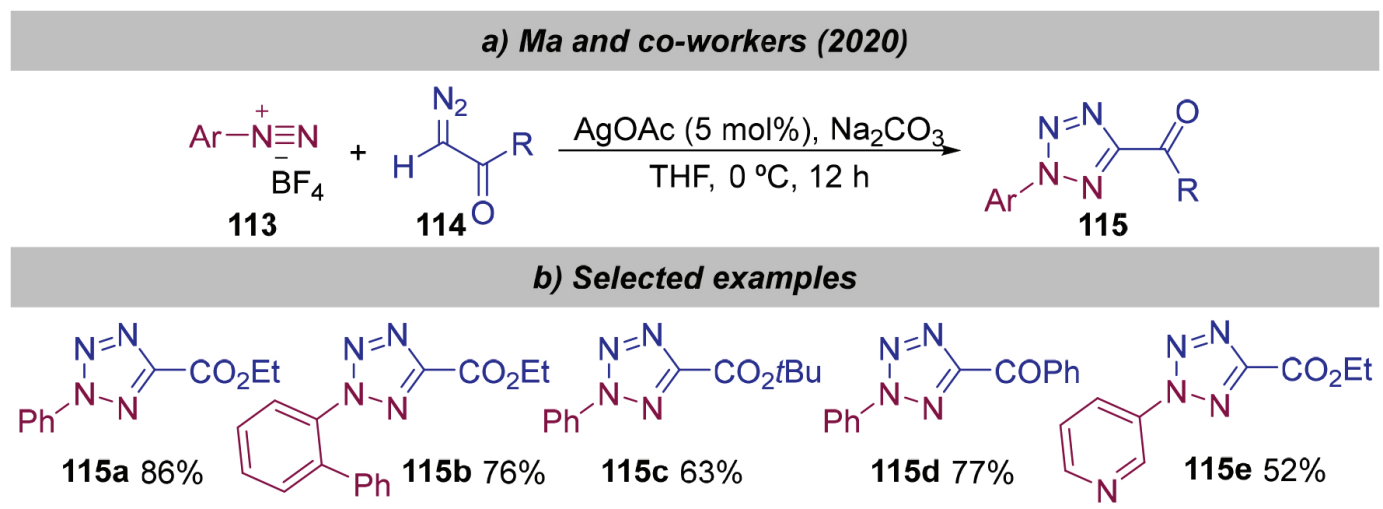

Scheme 22. Synthesis of carboxylic tetrazoles from arenediazonium salts and diazoacetates 


\section{a) Synthetic strageties towards isoxazoles}
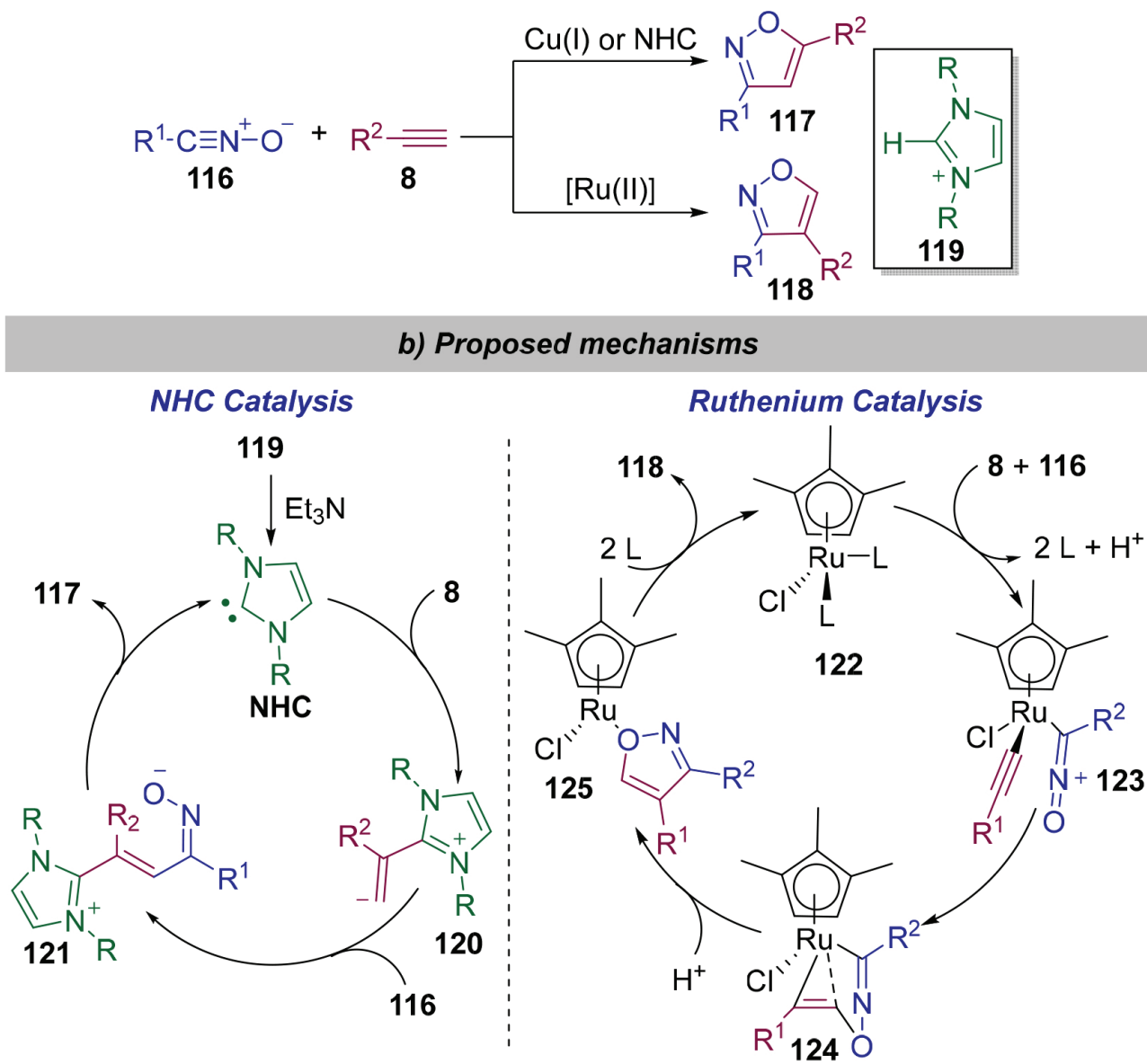

Scheme 23. Synthesis of 3,4- and 3,5-disubstituted isoxazoles using $\mathrm{Cu}, \mathrm{Ru}$ and $\mathrm{NHC}$ catalysts

a) Huang and co-workers (2019)
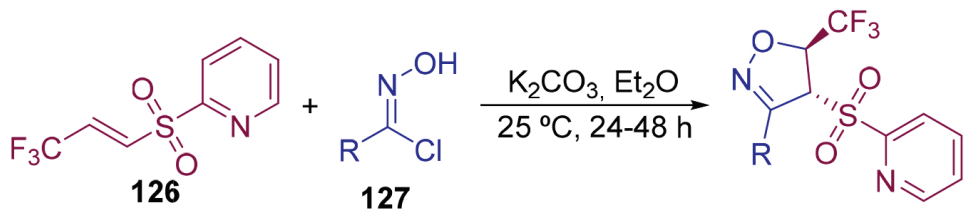

rac-128, $d r>99: 1$

major product<smiles>[R]C1=NO[C@H](S(=O)(=O)c2ccccn2)[C@@H]1C(F)(F)F</smiles>

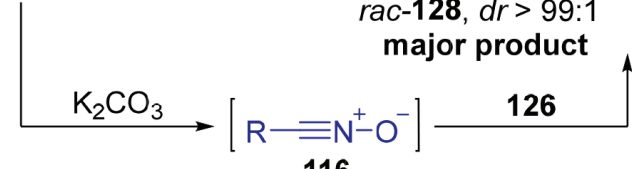

rac-129

116

\section{b) Selected examples}<smiles>O=S(=O)(c1ccccn1)[C@H]1C(c2ccccc2)=NO[C@@H]1C(F)(F)F</smiles>

128a $84 \%$<smiles>O=[N+]([O-])c1cccc(C2=NO[C@@H](C(F)(F)F)[C@H]2S(=O)(=O)c2ccccn2)c1</smiles><smiles>O=S(=O)(O)c1cccc(S(=O)(=O)[C@H]2C(C3CCCCC3)=NO[C@@H]2C(F)(F)F)n1</smiles>

Scheme 24. Synthesis of isoxazolines from $\beta$-fluoroalkyl-vinyl 2-pyridylsulfones and nitrile oxides generated in situ

derivatives 128 (Scheme 24). This base-catalyzed approach allowed the rapid access to several isoxazoles derivatives in moderate to good yields (Scheme 24b, 48-85\%)..$^{59}$

Other recent example that involves the generation of nitrile oxides in situ involves their formation in the presence of $\mathrm{Fe}$ (III) nitrate, as reported by $\mathrm{H} . \mathrm{Xu}, \mathrm{Y} . \mathrm{Xu}$ and co-workers (Scheme 25). ${ }^{60}$ As showed in Scheme $25 \mathrm{c}$, the alkyne $\mathbf{8}$ initially reacts with the iron salt, giving $\alpha$-nitroketone 132, which is further dehydrated to nitrile oxide $\mathbf{1 3 3}$. 
Next, the cycloaddition between 133 and iron-bonded nitrile 134 gives the 3-acyl-1,2,4-oxadiazole products $\mathbf{1 3 1}$.

In addition to nitrile oxides, nitrones may also be used as dipoles in 1,3-DC reactions to synthesize heterocyclic compounds. However, most reported procedures for the synthesis of isoxazolidine and isoxazoline derivatives often require drastic experimental conditions such as high temperature and long reaction times. Considering these facts, Chakraborty recently reported an efficient mechanochemical method for the synthesis of $N$-methyl- $C$-(2-furyl) nitrone $\mathbf{1 3 7}$ from furfural 135 and $N$-methylhydroxylamine 136 (Scheme 26a), as well as its 1,3-DC reaction with activated alkenes and electron deficient alkynes (Scheme 26b). In this sense, the 1,3-DC between 137 and substituted maleimides $\mathbf{1 3 8}$ led to the bicyclic isoxazolidines $\mathbf{1 3 9}$, while the reaction of $\mathbf{1 3 7}$ with internal alkynes $\mathbf{1 4 0}$ gave isoxazolines
141 (Scheme 26b). Importantly, the use of ball milling significantly increased the reaction rate and improved the yields. ${ }^{61}$

\section{Synthesis of imidazole, imidazoline and thiazole derivatives}

Another very interesting recent application of 1,3-DC reaction was reported recently by Angyal and co-workers, which developed a TFA-catalyzed protocol for the synthesis of imidazoles 144 from nitrones 142 and $2 \mathrm{H}$-azirines 143 (Scheme 27). ${ }^{62}$ By using this approach, over 30 1,2,4,5-tetrasubstituted imidazole derivatives were synthesized in moderate to good yields (Scheme 27b, 37-82\%). On the other hand, when azirines unsubstituted in the 2-position $\left(\mathrm{R}^{4}=\mathrm{H}\right)$ were used, only traces of the products were observed. In the proposed mechanism, the acid-activated azirine initially undergoes

a) H. Xu, Y. Xu and co-workers (2020)

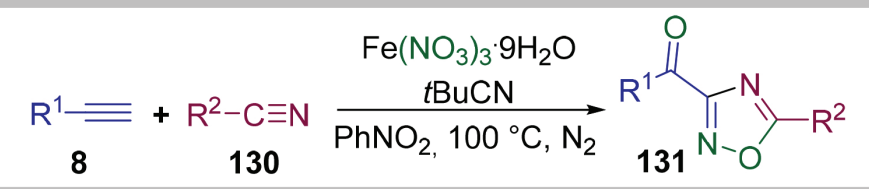

b) Selected examples

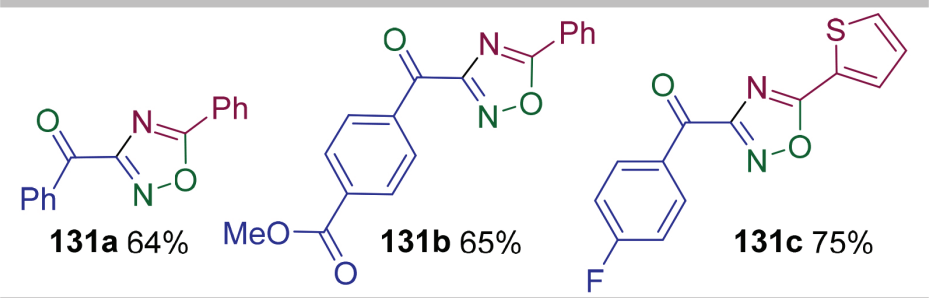

c) Proposed mechanism

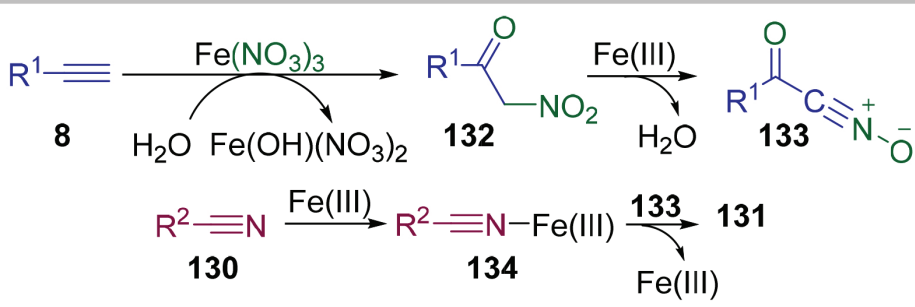

Scheme 25. Synthesis of 1,2,4-oxadiazole derivatives from alkynes and nitriles in the presence of iron(III) nitrate

\section{a) Synthesis of the nitrone partner}

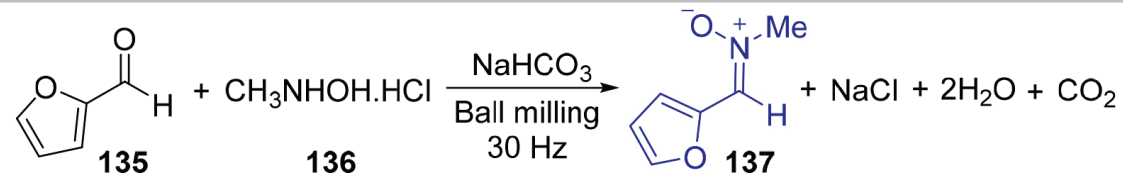

b) Synthesis of the isoxazolindine/isoxazoline derivatives

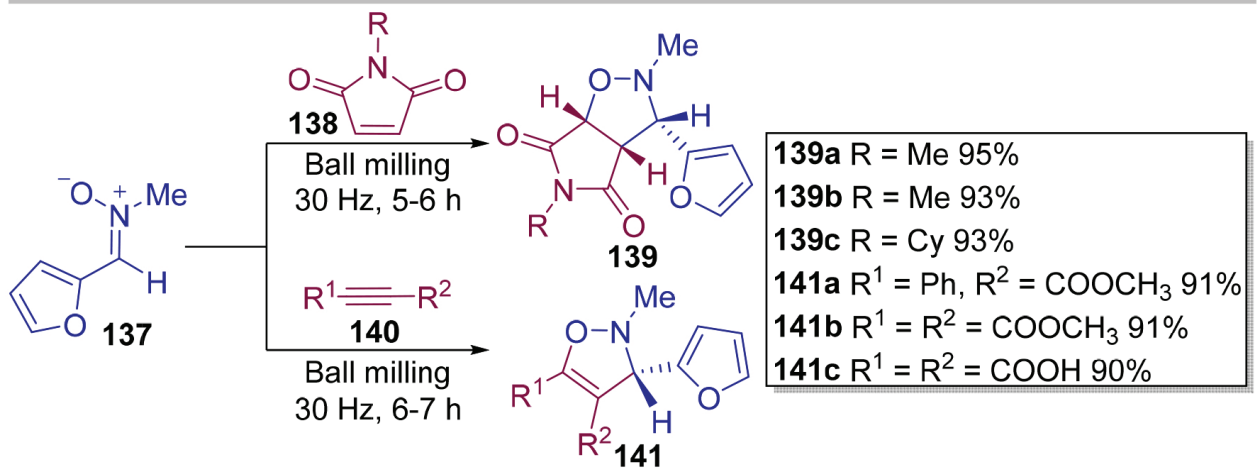


a 1,3-DC reaction with the nitrone partner $\mathbf{1 4 2}$, giving the expected intermediate $\mathbf{1 4 5}$ as product, but this molecule rapidly rearranges to ketoamidine 146, which then undergoes an intramolecular cyclization step to furnish hydroxyimidazoline 147 (Scheme 27c). Finally, the dehydration of $\mathbf{1 4 7}$ gives rise to the 1,2,4,5-tetrasubstituted imidazole product 144.

In a similar manner, Molina and co-workers have explored the reaction between $2 \mathrm{H}$-azirines $\mathbf{1 4 8}$ and azomethine ylides generated in situ from 149 to synthesize a series of enantiomeric enriched 1,3-diazabicyclo[3.1.0]hexanes $\mathbf{1 5 0}$ using a $\mathrm{Cu}(\mathrm{I}) /(\mathrm{R})$-Fesulphos catalytic system (Scheme 28a). ${ }^{63}$ Importantly, moderate to good yields were observed for the imidazoline-type products, as well as a high degree of enantioselectivity (Scheme 28a). In the proposed mechanism, compound 149 initially coordinates to the catalyst, giving 151, which leads to 152 after coordinating with $\mathbf{1 4 8}$. Next, a 1,3-DC and elimination of the catalyst gives products $\mathbf{1 5 0}$

a) Kanizsai and co-workers (2020)

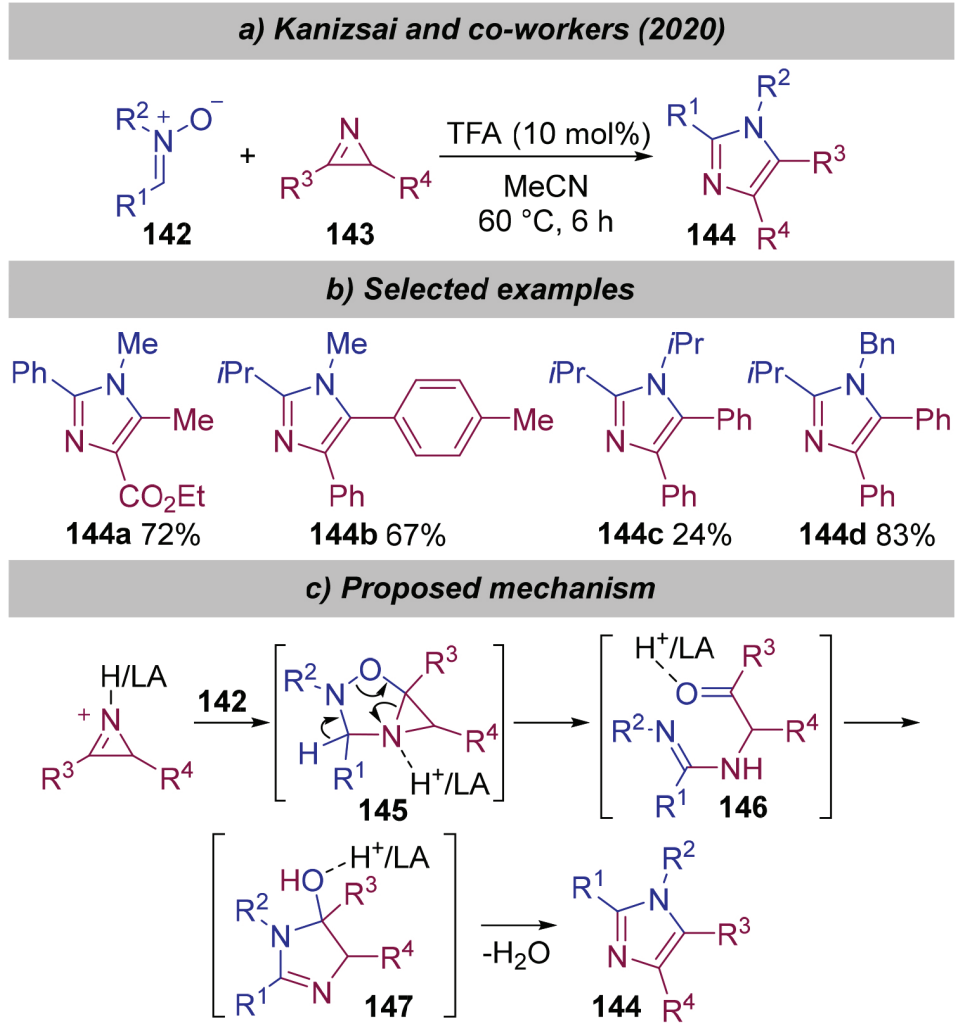

Scheme 27. Synthesis of 1,2,4,5-tetrasubstituted imidazoles

\section{a) Adrio, Carretero and co-workers (2020)}

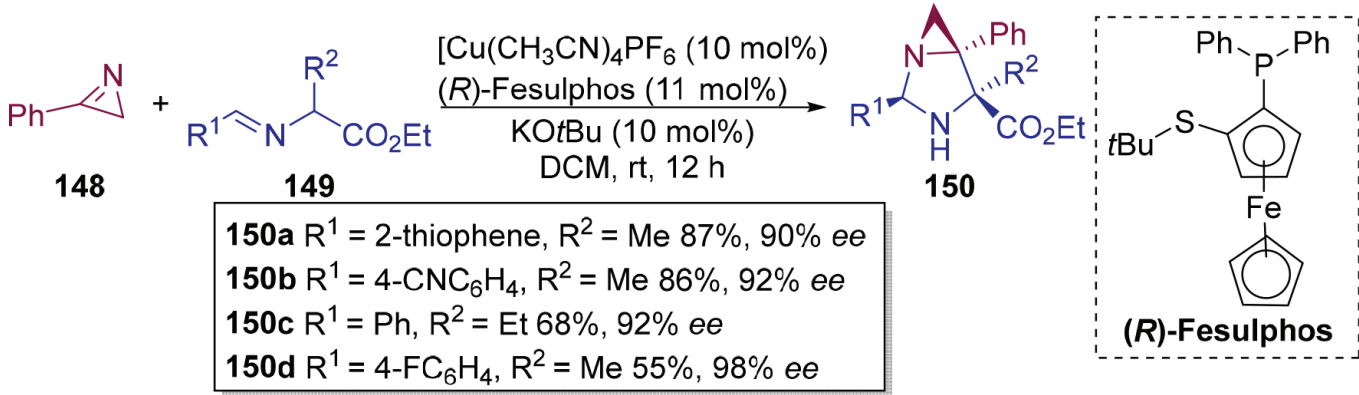

\section{b) Proposed mechanism}

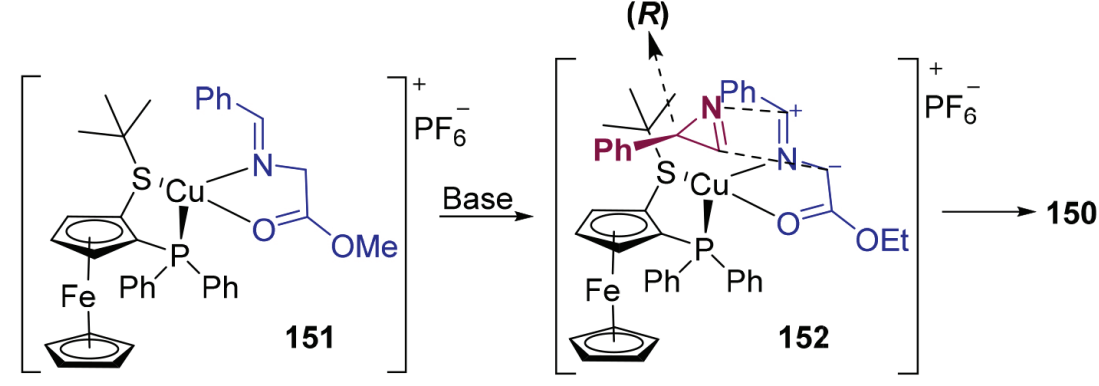


(Scheme 28b). It is important to highlight that the 2,3-disubstituted azirines approach the less hindered face of the chiral metallodipole, moving away from the $t \mathrm{Bu}$, the bulkiest group linked to the chiral catalyst.

In the same year, $\mathrm{Li}$ and co-workers reported the metal-free synthesis of thiazole-substituted $\alpha$-hydroxy carbonyls 155 from thiazole $N$-oxide 153 and olefins 154 (Scheme 29). ${ }^{64}$ The proposed mechanism involves the 1,3-DC between $\mathbf{1 5 3}$ and 154, resulting in the cyclic intermediate 156, which is further protonated, giving $\mathbf{1 5 7}$, and then re-aromatization takes place, leading to the products $\mathbf{1 5 5}$ (Scheme 29b).

\section{Synthesis of Other Heterocyclic Compounds}

Azomethine ylides are useful and highly reactive intermediates, which undergo a rapid cycloaddition with various olefins. Recently in
2020, Keesari and co-workers described the reaction of azomethine ylides generated in situ from isatins $\mathbf{1 5 8}$ and cyclic aminoacids $\mathbf{1 5 9}$ with Baylis-Hillman-type olefins $\mathbf{1 6 0}$ (Scheme 30). ${ }^{65}$ The use of such reagents in the presence of copper iodide under microwave irradiation proved to be a simple and rapid method to generate polycyclic frameworks 161 in a single step in moderate to good yields (Scheme $30 \mathrm{~b}, 62-84 \%)$. In the proposed mechanism, isatin 158 initially reacts with aminoacid $\mathbf{1 5 9}$, furnishing azomethine ylide 162 , which next undergoes a 1,3-DC reaction with 160, giving spiro-oxindole intermediate 163 (Scheme 30c). Subsequently, 163 undergoes a first intramolecular cyclization to produce 164, which after another intramolecular cyclization step, gives rise to product $\mathbf{1 6 1}$.

Also in 2020, Hou and co-workers reported the synthesis of spiropyrrolidines 168 through the enantioselective 1,3-DC azomethine ylides generated from 165 and $\alpha$-methylene- $\delta$-butyrolactone $\mathbf{1 6 6}$ (Scheme 31). ${ }^{66}$ In this case, cinchona-derived organocatalyst 167

\section{a) Song and co-workers (2020)}

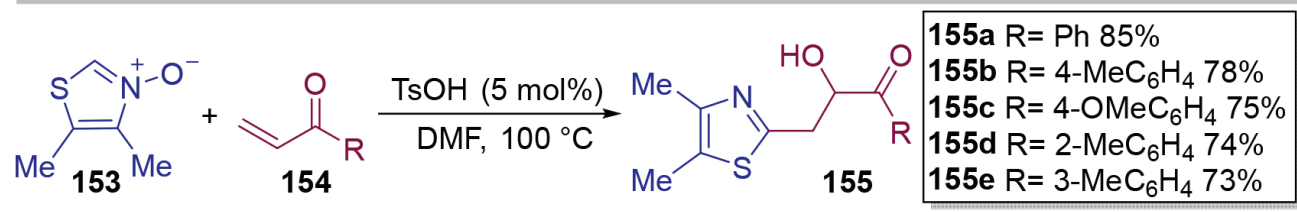

\section{b) Proposed mechanism}

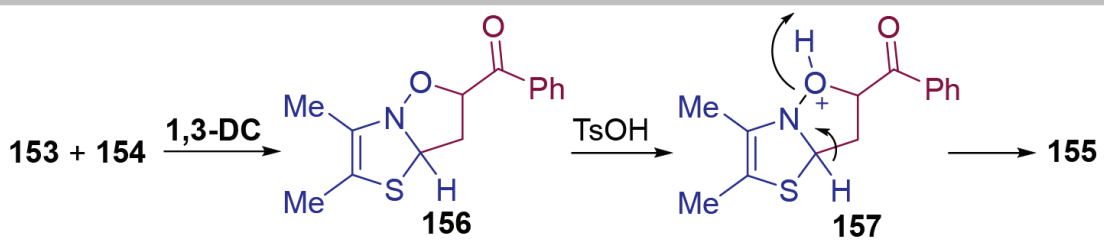

Scheme 29. Synthesis of thiazole-substituted $\alpha$-hydroxy carbonyls from thiazole $N$-oxide and olefins

\section{a) Reddy and co-workers (2020)}<smiles>[R15]c1cccc2c1NC(=O)C2=O</smiles>

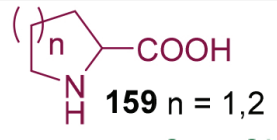<smiles>C=C(C(=O)OCC)C(O)c1ccc(I)cc1</smiles>

Cul $(20 \mathrm{~mol} \%)$

MW, DMF, $80^{\circ} \mathrm{C}, 10 \mathrm{~min}$

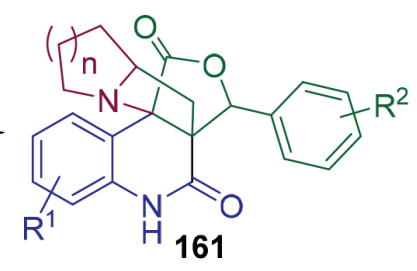

\section{b) Selected examples}<smiles></smiles>

161 a $68 \%$<smiles>CCCC12c3ccccc3NC(=O)C13CC2C(=O)OC3C(C)C</smiles>

161b $80 \%$<smiles>CN1CCC23C(=O)Nc4ccc(Cl)cc4C2(CC(C)(C)C)C(=O)OC3c2ccccc21</smiles>

161c $68 \%$

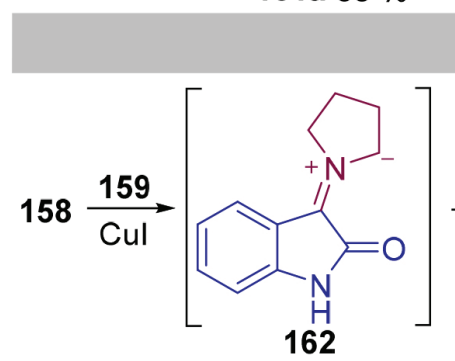

c) Proposed mechanism

160<smiles>CCOC(=O)C1(C(=O)O)CC2CCCN2C12c1ccccc1NC(=O)C2(O)c1ccccc1</smiles><smiles>CCSC</smiles><smiles>C/C=C\CCCCCC</smiles><smiles>CCOC(=O)C1(c2ccccc2)CC2(c3ccccc3[N+](=O)[O-])C(=O)OC1C21CCCC1</smiles>

Scheme 30. Synthesis of fused heterocycles from isatins, aminoacids and Baylis-Hillman-type olefins 
was used in the presence of silver oxide, leading to the corresponding products in high yields and enantioselectivity (78-96\% yield, $75-93 \%$ ee, Scheme 31b).

Jin and co-workers also gave their contribution to this field in 2019, having reported the reaction between nitroindoles 169 and dipoles formed from allenoates $\mathbf{1 7 0}$ to synthesize fused-indole derivatives 171 under phosphine catalysis (Scheme 32). ${ }^{67}$ Over 20 examples were synthesized using this protocol, and moderate to good yields were observed (Scheme 32b, 40-82\%). The proposed mechanism starts with the transformation of the allene ester $\mathbf{1 7 0}$ into 1,3-dipole 172 in the presence of triphenyl phosphine, which next undergoes an addition step with nitroindole 169, giving transient intermediate 173 (Scheme 32c). Subsequently, an intramolecular cyclization step leads to intermediate $\mathbf{1 7 4}$, which upon proton shift, furnished 175. Finally, product $\mathbf{1 7 1}$ is formed upon the release of triphenyl phosphine.
Carbonyl ylides are another type of dipole widely used in 1,3-DC reactions, affording polycyclic ring systems containing a tetrahydrofuran moiety. Due to their high reactivity, such compounds must be produced in situ, and are often obtained from the interaction of a carbene or metallocarbene with the oxygen atom of a carbonyl group. ${ }^{68}$ On the other hand, carbonyl ylides such as $\mathbf{1 7 8}$ can be obtained via the Diels-Alder reaction between 1,3,4-oxadiazoles $\mathbf{1 7 6}$ and alkenes followed by the elimination of molecular nitrogen (Scheme 33a). ${ }^{69}$ Inspired by these concepts, Sears and Boger developed an intramolecular version of this reaction and explored its applications in the synthesis of natural products (Scheme $33 \mathrm{~b}$ ). ${ }^{70}$ By using substrates containing both the initiating dienophile and subsequent dipolarophile tethered to the 1,3,4-oxadiazoles 180, this intramolecular Diels Alder/1,3-DC sequence allowed the use of diverse dienophiles and dipolarophiles, as well as unsymmetrical dienophiles and dipolarophiles with high regioselectivity. The protocol

a) Wang and co-workers (2020)

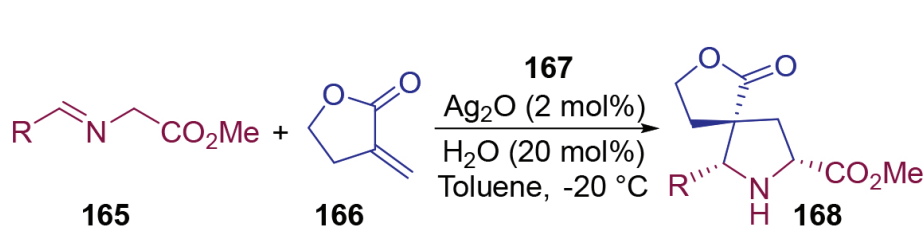

165

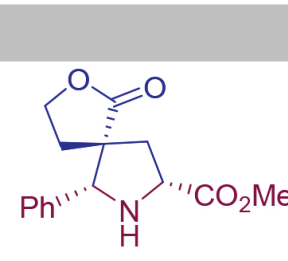

168a $94 \%, 93 \%$ ee

b) Selected examples<smiles>COC(=O)[C@@H]1C[C@@]2(CCOC2=O)[C@H](c2ccccc2F)N1</smiles>

168b $91 \%$, 92\% ee

168c $93 \%, 91 \%$ ee

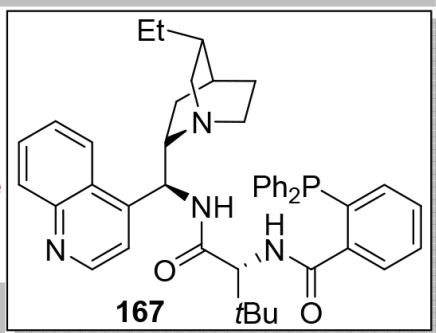<smiles>COc1ccccc1[C@@H]1N[C@H](C(C)=O)C[C@]12CCOC2=O</smiles><smiles>COC(=O)[C@@H]1C[C@]2(CCOC2=O)[C@H](c2ccccc2)N1</smiles>

168d $94 \%$, $90 \%$ ee

Scheme 31. Enantioselective synthesis of spiro-[butyrolactone-pyrrolidine]

a) Mei, Shi and co-workers (2019)

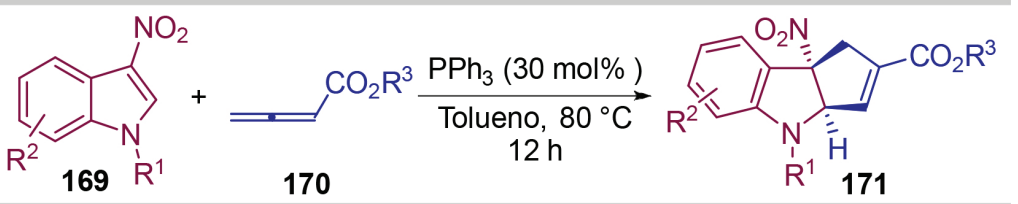

b) Selected examples<smiles>CCOC(=O)C1=C[C@H]2N(C(C)=O)c3ccccc3[C@]2(NO)C1</smiles>

171a $80 \%$<smiles>CCOC(=O)C1=C[C@H]2N(C(=O)c3ccccc3)c3ccc(F)cc3[C@]2(N)C1</smiles>

$171 \mathrm{~b} 81 \%$

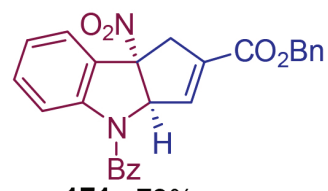

171c $73 \%$

c) Proposed mechanism

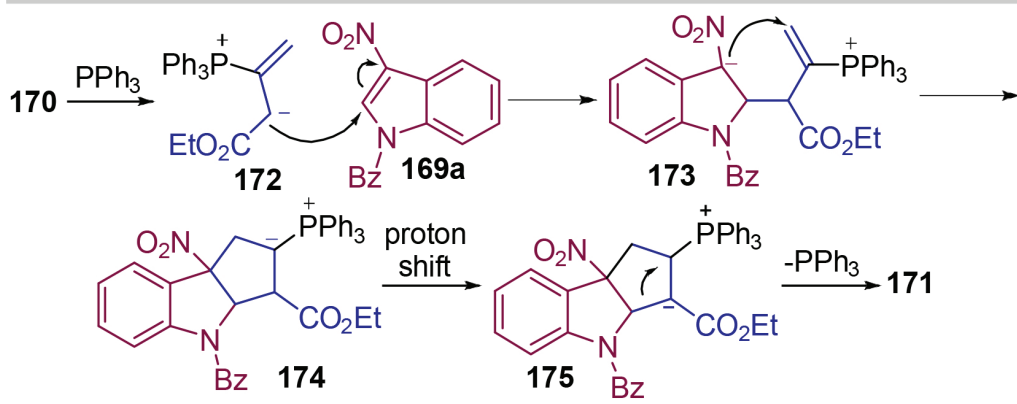

Scheme 32. Synthesis of indole-fused five-membered rings from nitroindoles and allenoates 
a) Intermolecular 1,3-DC between 1,3,4-oxadiazoles and alkenes
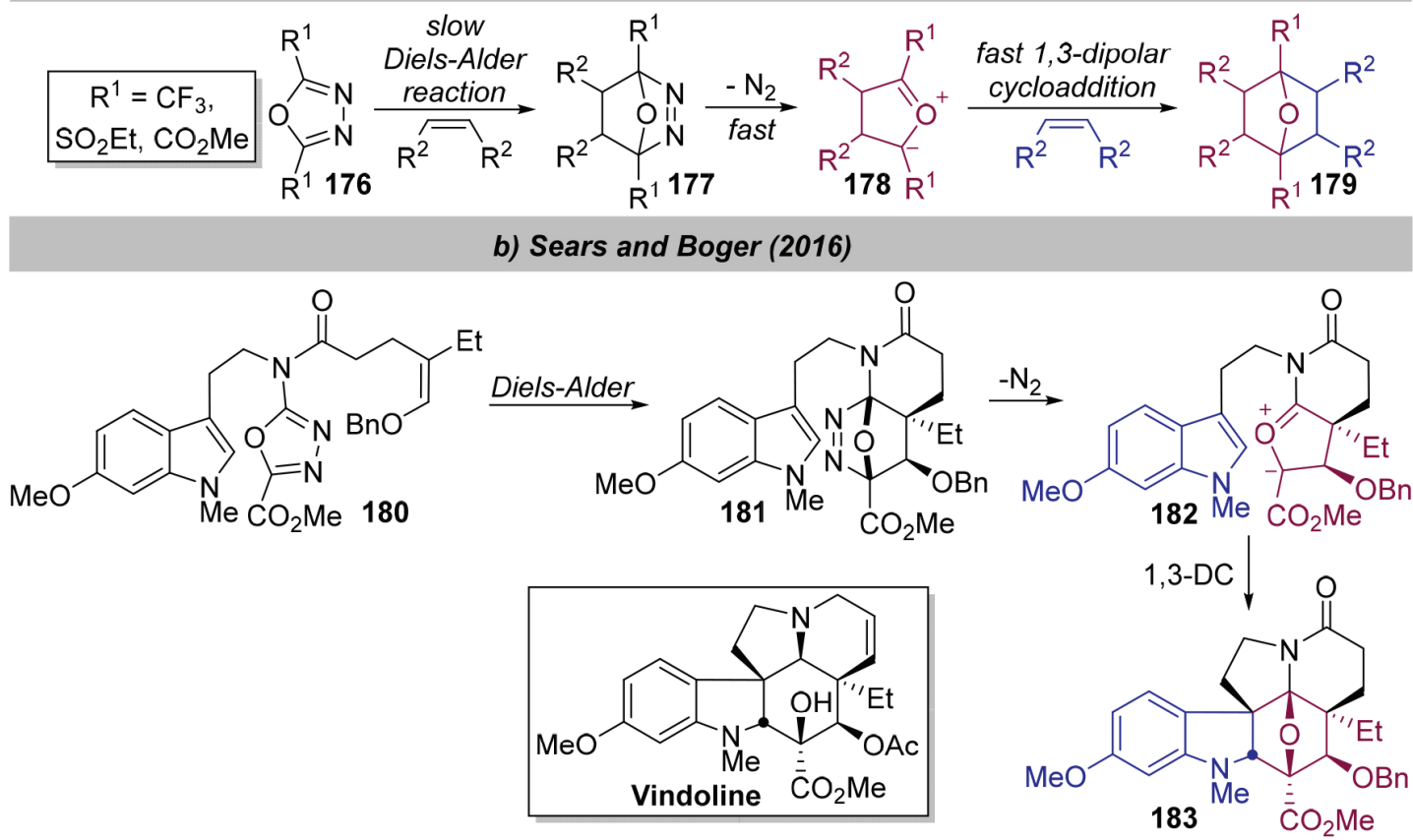

Scheme 33. 1,3-DC reaction between in situ-generated carbonyl ylides and alkenes

could be successfully applied to the synthesis of the alkaloids $(-)$-vindoline and (-)-vindorosine, and other natural products such as (+)-4-desacetoxyvindoline, (+)-4-desacetoxyvindorosine, minovine, $(+)-N$-methylaspidospermidine, $(+)$-spegazzinine and $(-)$-aspidospermine.

\section{FINAL REMARKS}

1,3-dipolar cycloaddition is a very important set of reactions for organic synthesis, an excellent alternative for the preparation of fivemembered heterocycles and for expanding chemical diversity for the discovery of new biologically active compounds. There is no doubt that Huisgen was the scientist who most impelled this chemistry, which remains a set of important reactions of interest to synthetic chemists. Huisgen himself stated in one of his publications: "The 1,3-dipolar addition offers a remarkably wide range of utility in the synthesis of five-membered heterocycles". In all the years he was in charge of his research group, he was extremely creative and formed many new generations of great researchers. This text is a tribute to this remarkable scientist who contributed significantly to the development of chemistry. We hope that the examples discussed herein pique the interest of the younger generations of synthetic organic chemists.

\section{REFERENCES}

1. Huisgen, R. In The Adventure Playground of Mechanisms and Novel Reactions (Profiles, Pathways, and Dreams); Seeman, J. Y., ed.; American Chemical Society: Washington, D.C., 1994.

2. Breugst, M.; Reissig, H.; Angew. Chem., Int. Ed. 2020, 59, 2.

3. https://www.chemistryviews.org/details/ezine/11230823/Rolf_ Huisgen_1920_2020.html?utm_source=dlvr.it\&utm_medium=twitter, accessed on September, 2020.

4. Huisgen, R.; Angew. Chem., Int. Ed. Engl. 1963, 2, 565.

5. Wolwski, W. L. In 1,3-Dipolar Cycloaddition Reaction; Padwa, A., ed.; Jonh Wiley \& Sons: New York, 1984, vol. 1, p.559.

6. Maiuolo, L.; Algieri, V.; Olivito, F.; de Nino, A.; Catalysts 2020, 10, 65.
7. Huisgen, R.; Pöchlauer, P.; Mlostoń, G.; Polborn, K.; Helv. Chim. Acta 2007, 90, 983.

8. Huisgen, R.; Langhals, E.; Heteroatom Chem. 2006, 17, 433.

9. Huisgen, R.; J. Org. Chem. 1976, 41, 403.

10. Huisgen, R.; Szeimies, G.; Möbius, L.; Chem. Ber. 1967, 100, 2494.

11. Buchner, E.; Ber. Dtsch. Chem. Ges. 1888, 21, 2637.

12. Smith, L. I.; Chem. Rev. 1938, 23, 193.

13. Woodward, R.B.; Hoffmann, R.; The Conservation of Orbital Symmetry; Academic Press: New York, 1970.

14. Merlo, A. A.; Reações Pericíclicas: uma Sinfonia de Moléculas e Elétrons; Editora UFRGS: Porto Alegre, 2012.

15. Katritzky, A. L.; Zhang, Y.; Singh, S. K.; Heterocycles 2003, 60, 1225.

16. Giera, H.; Huisgen, R.; Langhals, E.; Polborn, K.; Helv. Chim. Acta 2002, 85,1523

17. Houk, K. N.; Acc. Chem. Res. 1975, 8, 361.

18. Gothelf, K. V.; Jorgensen, K. A.; Chem. Rev. 1998, 98, 863.

19. Kanemasa, S.; Synlett 2002, 1371.

20. Pellissier, H.; Tetrahedron 2007, 63, 3235.

21. Osborn, H. M. I.; Gemmell, N.; Harwood, L. M.; J. Chem. Soc., Perkin Trans. 1 2002, 2419.

22. Kumar, S.; Kumar, V. Singh, S. P.; Pericyclic Reactions: A Mechanistic and Problem Solving Approach, Academic Press, 2016.

23. Bakulev, V. A.; Beryozkina,T.; Thomas, J.; Dehaen, W.; Eur. J. Org. Chem. 2018, 262.

24. Dheer, D.; Singh, V.; Shankar, R.; Bioorg. Chem. 2017, 71, 30.

25. Michael, A.; J. Prakt. Chem. 1893, 46, 94.

26. Tornøe, C. W.; Christensen, C.; Meldal, M.; J. Org. Chem. 2002, 67, 3057.

27. Rostovtsev, V. V.; Green, L. G.; Fokin, V. V.; Sharpless, K. B.; Angew. Chem., Int. Ed. 2002, 41, 2596.

28. Rodionov, V. O.; Fokin, V. V.; Finn, M. G.; Angew. Chem., Int. Ed. 2005, 44, 2210; Worrell, B. T.; Malik, J. A.; Fokin, V. V.; Science 2013, 340, 457; Iacobucci, C.; Reale, S.; Gal, J.-F.; de Angelis, F.; Angew. Chem., Int. Ed. 2015, 54, 3065; Jin, L.; Tolentino, D. R.; Melaimi, M.; Bertrand, G.; Sci. Adv. 2015, 1, e1500304; Özkılıç, Y.; Tüzün, N. Ş.; Organometallics 2016, 35, 2589; Ziegler, M. S.; Lakshmi, K. V.; Tilley, T. D.; J. Am. Chem. Soc. 2017, 139, 5378. 
29. Zhang, L.; Chen, X.; Xue, P.; Sun, H. H. Y; Williams, I. A. D.; Sharpless, K. B.; Fokin, V. V.; Jia, G.; J. Am. Chem. Soc. 2005, 127, 15998.

30. Guimarães, T. T.; Pinto, M. C. F. R.; Lanza, J. S.; Melo, M. N.; do Monte-Neto, R. L.; de Melo, I. M. M.; Diogo, E. B. T.; Ferreira, V. F.; Camara, C. A.; Valença, W. O.; de Oliveira, R. N.; Frézard, F.; Júnior, E. N. S.; Eur. J. Med. Chem. 2013, 63, 523.

31. Liao, Y.; Lu, Q.; Chen, G.; Yu, Y.; Li, C.; Huang, X.; ACS Catal. 2017, 7, 7529 .

32. Zeng, L.; Lai, Z.; Zhang, C.; Xie, H.; Cui, S.; Org. Lett. 2020, 22, 2220.

33. Agard, N. J.; Prescher, J. A.; Bertozzi, C. R.; J. Am. Chem. Soc. 2004, 126, 15046.

34. Rogue, D. R.; Neill, J. L.; Antoon, J. W.; Stevens, E. P.; Synthesis 2005, 2497.

35. Amantini, D.; Fringuelli, F.; Piermatti, O.; Pizzo, F.; Zunino, E.; Vaccaro, L.; J. Org. Chem. 2005, 70, 6526.

36. Campos, V. R.; Cunha, A. C.; Silva, W. A.; Ferreira, V. F.; de Sousa, C. S.; Fernandes, P. D.; Moreira, V. N.; da Rocha, D. R.; Dias, F. R. F.; Montenegro, R. C.; de Souza, M. C. B. V.; Boechat, F. C. S.; Franco, C. F. J.; Resende, J. A. L. C.; RSC Adv. 2015, 5, 96222.

37. Pourakbari, R.; Taher, S. M.; Mosayyebi, B.; Ayoubi-Joshaghani, M. H.; Ahmadi, H.; Aghebati-Maleki, L.; Int. J. Biol. Macromol. 2020, 163, 1323.

38. Gurung, R. B.; Gong, S. Y.; Dhakal, D.; Le, T. T.; Jung, N. R.; Jung, H. J.; Oh, T. J.; Sohng, J. K.; J. Microbiol. Biotechnol. 2017, 27, 1639.

39. Singh, H.; Khanna, G.; Khurana, J. M.; Tetrahedron Lett. 2016, 57, 3075.

40. Duan, X.; Huang, X.; Fu, C.; Ma, S.; Adv. Synth. Catal. 2020, 362, 627.

41. Dimroth, O.; Justus Liebigs Ann. Chem. 1909, 364, 183.

42. Dimroth, O.; Michaelis, W.; Justus Liebigs Ann. Chem. 1927, 459, 39.

43. Fabian, W. M. F.; Bakulev, V. A.; Kappe, C. O.; J. Org. Chem. 1998, 63, 5801.

44. Melo, J. O. F.; Donnici, C. L.; Augusti, R.; Ferreira, V. F.; de Souza, M. C. B. V.; Ferreira, M. L. G.; Cunha, A. C.; Quim. Nova 2006, 29, 569.

45. L'Abbe, G.; J. Heterocycl. Chem. 1984, 21, 627.

46. El Ashry, E. S. H.; Nadeem, S.; Shah, M. R.; Kilany, Y. E.; Adv. Heterocycl. Chem. 2010, 101, 161.

47. Subbotina, J. O.; Fabian, W. M. F.; Tarasov, E. V.; Volkova, N. N.; Bakulev, V. A.; Eur. J. Org. Chem. 2005, 2914.

48. Huang, Y.; Ren, D.; Yu, X.; Zeng, J.-L.; Li, X.; Chem. Heterocycl. Compd. 2020, 56, 84 .
49. Nájera, C.; Sansano, J. M.; Yus, M.; Org. Biomol. Chem. 2015, 13, 8596.

50. Shintani, R.; Fu, G. C.; J. Am. Chem. Soc. 2003, 125, 10778.

51. Wang, X.; Yang, P.; Zhang, Y.; Tang, C.-Z.; Tian, F.; Peng, L.; Wang, L.-X.; Org. Lett. 2017, 19, 646.

52. Shi, Y.; Wang, G.; Chen, Z.; Wu, M.; Wang, J.; Trigoura, L.; Guo, H.; Xing, Y.; Sun, S.; J. Heterocycl. Chem. 2020, 57, 2044.

53. Tupychak, M. A.; Shyyka, O. Y.; Pokhodylo, N. T.; Obushak, M. D.; RSC Adv. 2020, 10, 13696.

54. Ramu, G.; Tangella, Y.; Ambala, S.; Babu, B. N.; J. Org. Chem. 2020, 85,5370 .

55. Adrio, J.; Carretero, J. C.; Chem. Commun. 2019, 55, 11979.

56. Fang, X.; Wang, C.-J. Org.; Biomol. Chem. 2018, 16, 2591.

57. Xiao, M.-Y.; Chen, Z.; Zhang, F.-G.; Ma, J.-A.; Tetrahedron 2020, 76, 131063.

58. Heaney, F.; Eur. J. Org. Chem. 2012, 3043.

59. Ou, Z.; Huang, Q.; Kou, Y.-D.; Cheng, F.; Kalita, S. J.; Zhao, Z.-N.; Huang, Y.-Y.; Asian J. Org. Chem. 2019, 8, 2184.

60. Bian, Q.; Wu, C.; Yuan, J.; Shi, Z.; Ding, T.; Huang, Y.; Xu, Y.; Xu, H.; J. Org. Chem. 2020, 85, 4058.

61. Chakraborty, B.; J. Heterocycl. Chem. 2019, 1.

62. Angyal, A.; Demjén, A.; Wölfling, J.; Puskás, L. G.; Kanizsai, I.; J. Org. Chem. 2020, 85, 3587.

63. Molina, A.; Díaz-Tendero, S.; Adrio, J.; Carretero, J. C.; Chem. Commun. 2020, 56, 5050.

64. Li, H.; Zhang, J.; Zhang, Y.; Wang, J.; Song, G.; Tetrahedron Lett. 2019, 60, 150825 .

65. Keesari, N. R.; Mudavath, S.; Rao, M. V. K.; Sridhar, B.; Reddy, B. V. S.; Synth. Commun. 2020, 50, 973.

66. Hou, Q.; You, Y.; Song, X.; Wang, Y.; Chen, K.; Wang, H.; Catalysts 2020, 10, 28.

67. Jin, L.-W.; Jiang, F.; Chen, K.-W.; Du, B.-X.; Mei, G.-J.; Shi, F.; Org. Biomol. Chem. 2019, 17, 3894.

68. Hodgson, D. M.; Pierard, F. Y. T. M.; Stupple, P. A.; Chem. Soc. Rev. 2001, 30, 50 .

69. Margetic, D; Troselj, P.; Johnston, M. R.; Mini Rev. Org. Chem. 2011, $8,49$.

70. Sears, J. E.; Boger, D. L.; Acc. Chem. Res. 2016, 49, 241. 